\title{
Nurse Talk: Features of effective verbal communication used by expert District Nurses
}

\author{
by \\ Lindsay Margaret Macdonald \\ A thesis submitted to Victoria University of Wellington \\ in partial fulfilment \\ of requirements for the degree of \\ Master of Arts (Applied) \\ in Nursing
}

Victoria University of Wellington 


\section{Abstract}

This thesis represents an appreciative enquiry to identify features of effective verbal communication between nurses and patients.

Using a method developed by the Language in the Workplace Project (Stubbe 1998) two nurse participants recorded a small sample of their conversations with patients as they occurred naturally in clinical practice. These six conversations constitute the main body of raw data for the study. The data was analysed using a combination of discourse and ethnographic analysis.

Experience in nursing, particularly insider knowledge of the context of district nursing, helped me to uncover the richness of meaning in the conversations. The subtle interconnections and nuances could easily have been missed by an outside observer.

The study has shown that in their interactions with patients, expert nurses follow a pattern in terms of the structure and content of the conversations and it is possible to identify specific features of effective nurse-patient communication within these conversations. The most significant of these are the repertoire of linguistic skills available to nurses, the importance of small talk and the attention paid by nurses to building a working relationship with patients, in part, through conversation.

The findings have implications for nursing education and professional development. 


\section{Acknowledgements}

Words are important.

It has been my good fortune to work alongside nurses who have shown me the effectiveness of their timely words of enquiry, understanding, information and encouragement. To these nurses and the patients we work with, I acknowledge a large debt of gratitude.

To Jan Duke for her guidance, patience and steady support I am especially grateful.

My particular thanks go to Janet Holmes for her generosity and inclusiveness in opening up the world of linguistics to me and for her unfailing enthusiasm.

To friends and family who have endured the glacial speed with which this project has progressed, you have each played a special and important part and are now free of it. 


\section{Contents}

Abstract

Acknowledgements …….......................................................................................ii

1 Introduction

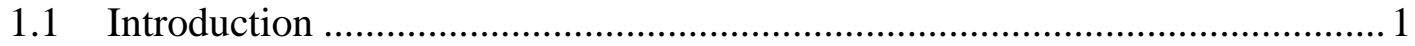

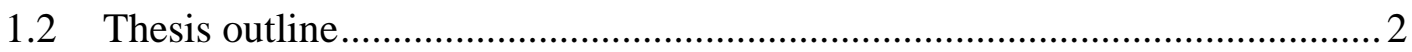

2 Literature Review

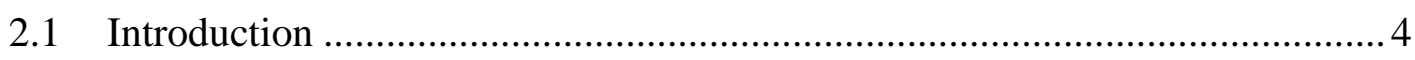

2.1.1 Communication in the workplace ......................................................... 5

2.2 The importance of communication .............................................................. 6

2.2.1 Patient satisfaction and complaints ........................................................ 7

2.2.2 Beneficial effects of giving information ............................................. 7

2.2.3 Interviewing skills to identify patient concerns ...................................... 8

2.2.4 Collaboration in the nurse-patient relationship ..................................... 10

2.2.5 Communication in itself can be therapeutic...........................................11

2.3 Contextual factors affecting communication in the nurse/patient relationship ... 11

2.3.1 Setting in time and place ...................................................................... 12

2.3.2 Knowing the patient .......................................................................... 13

2.3.3 Nature of the health issues ................................................................... 15

2.4 Attributes of an effective nurse communicator ...............................................16

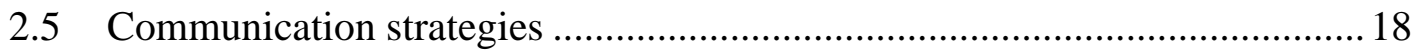

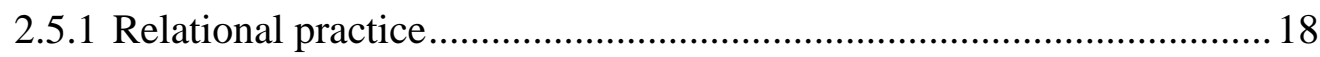

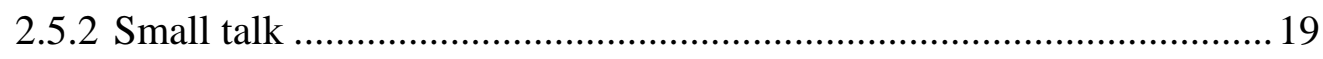


2.5.3 Translating, blending, accommodating in conversation ..................... 20

2.6 Appreciative enquiry; a study of expert nurse-patient communication.......... 22

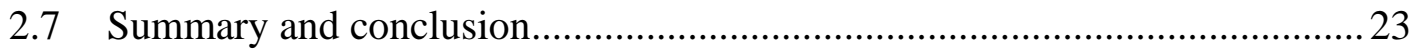

3 Methodology

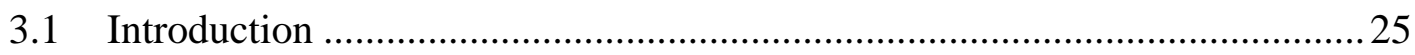

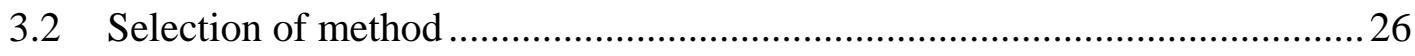

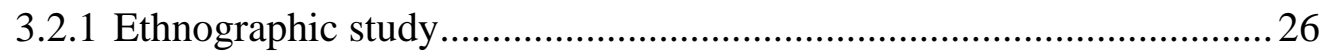

3.2.2 The Language in the Workplace methodology ................................. 29

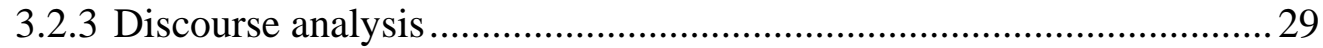

\subsection{Study Design}

3.3.1 Preparatory work and pilot study ................................................. 30

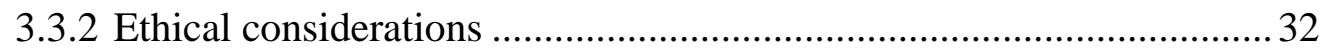

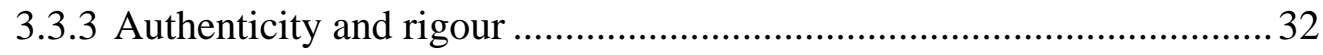

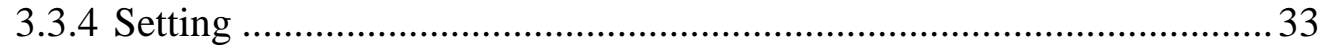

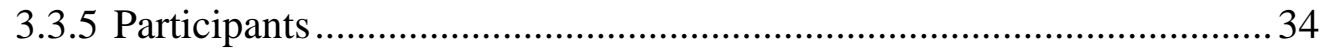

3.3.6 How the participants were selected............................................... 35

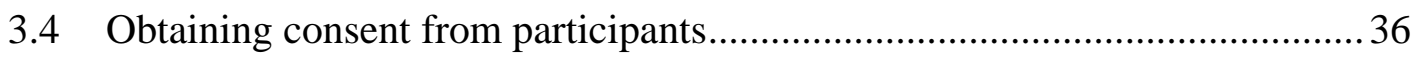

3.5 Data collection

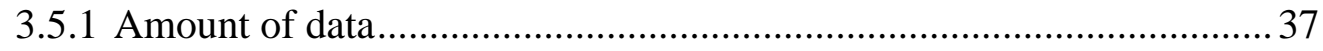

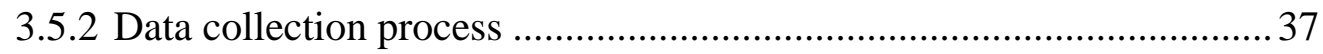

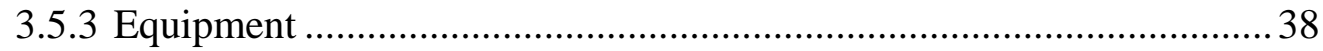

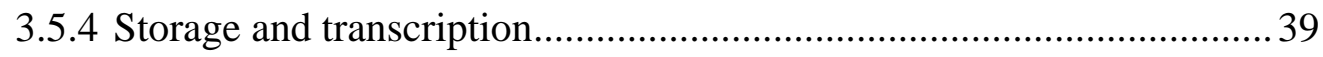

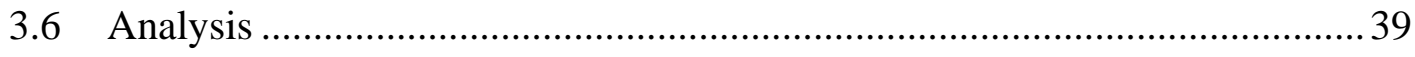

3.7 Reflection on the process / Discussion ................................................. 40

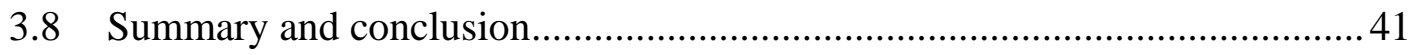


4 Analysis of recorded conversations: Setting the scene

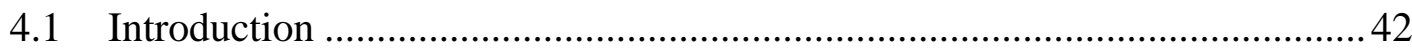

4.2 Purpose of conversations: explicit and implicit........................................ 43

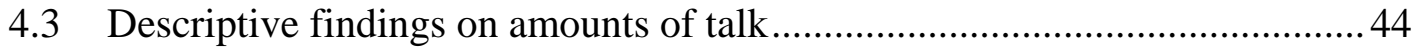

4.3.1 Gender and power in conversations ................................................ 44

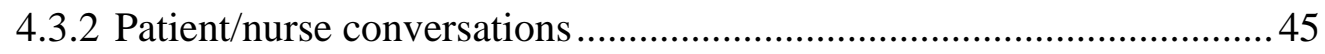

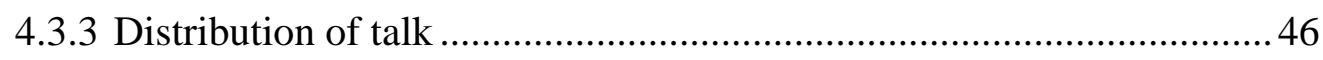

4.3.3.1 On-topic versus off-topic talk............................................ 48

4.4 What was said: the content of the conversations ...................................... 49

4.5 How it was said (the linguistic repertoire of the nurses) ..............................50

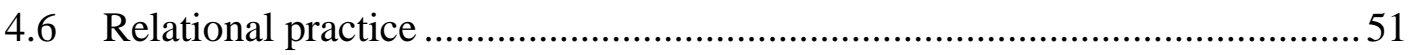

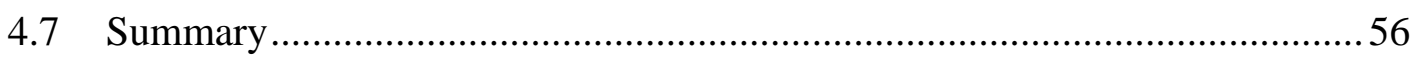

5 Analysis of recorded conversations: Structure and Content

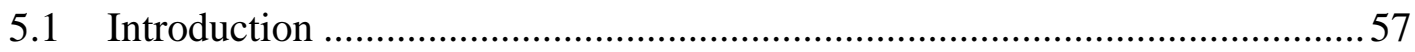

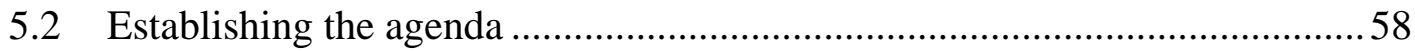

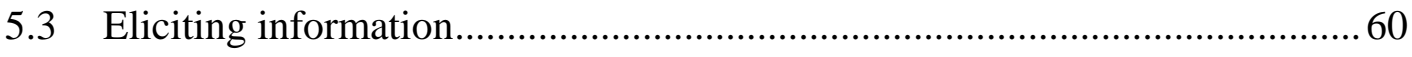

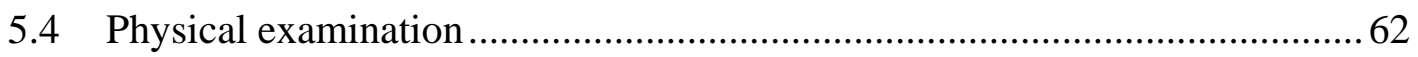

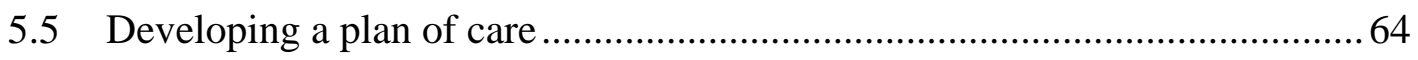

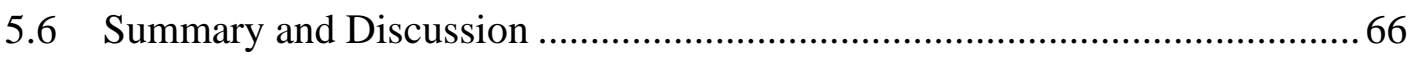

6 Analysis of recorded conversations: Linguistic repertoire of the nurses

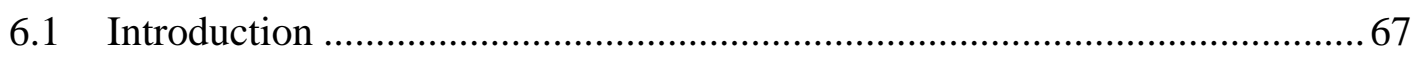

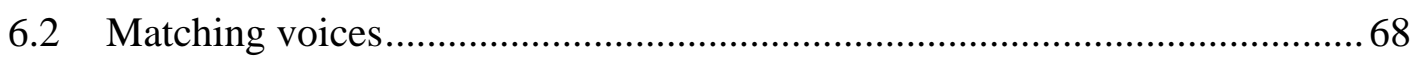

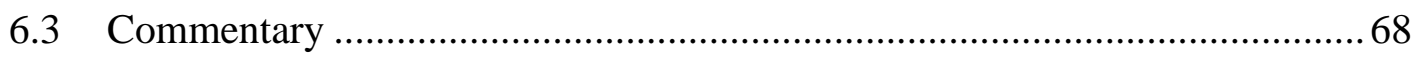

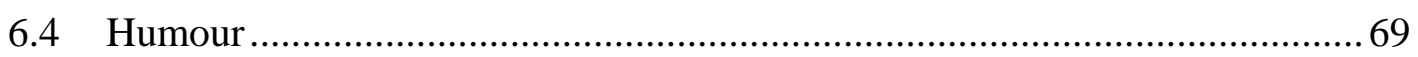

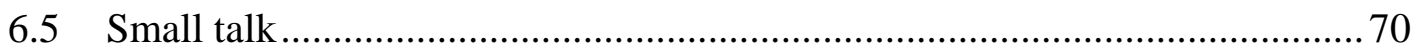

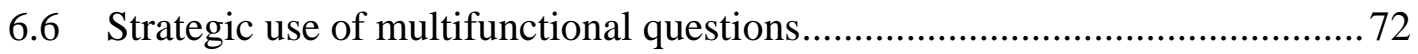

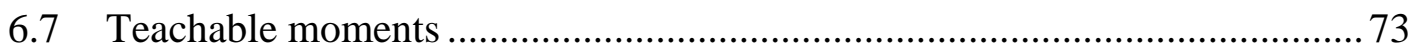

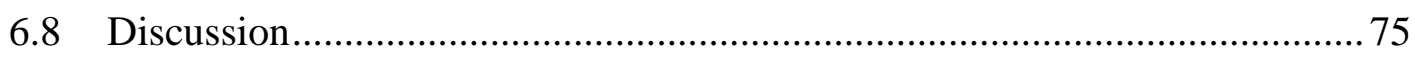


7 Discussion, Recommendations and Summary

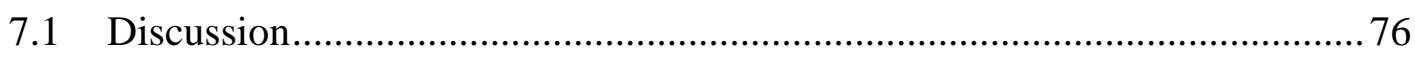

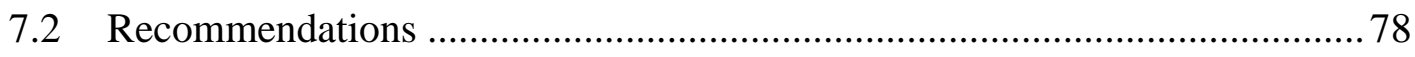

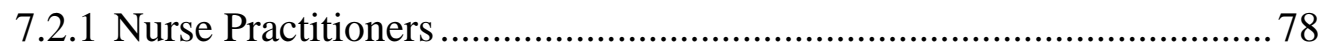

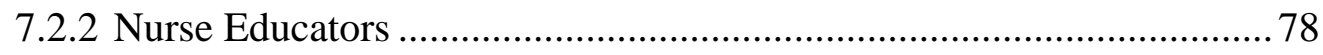

7.2.3 Nurse Managers ................................................................................. 79

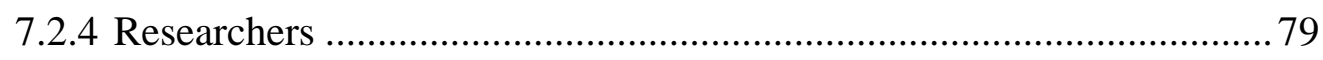

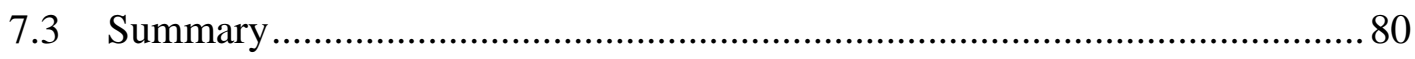

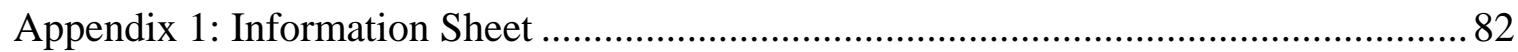

Appendix 2: Consent Form ……………………………............................................ 83

Appendix 3: Transcription Conventions ......................................................................... 84

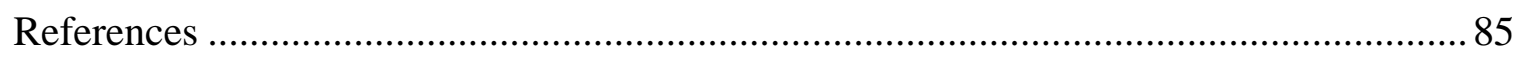

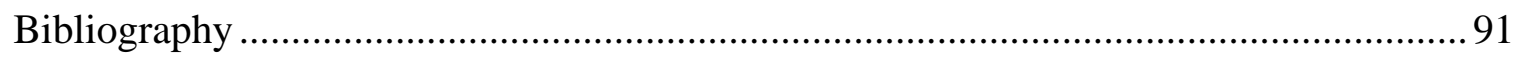




\section{Chapter 1}

\section{Introduction}

\subsection{Introduction}

"Communication forms the foundation of all nursing care yet strangely, it is an area of nursing which has often been taken for granted or underestimated.” (Macleod-Clarke, 1984, p.52).

One area of particular interest for me, and the focus of this thesis, is the search for evidence of expert nursing practice in the way nurses conduct everyday conversations in clinical practice; the role of language and communication as a factor contributing to nursing effectiveness.

In my current practice I have a responsibility for the clinical practice of a team of nurses working in a domiciliary setting. It has been my area of clinical practice for the last 12 years. Here, a great deal of nursing work is embedded in everyday conversations between nurses and patients as the nurse establishes a rapport, elicits information, gives out information and develops a plan of care. 
My experience in nursing, combined with an interest in language, has led me to speculate about whether the language (the actual words) used by nurses has an effect on clinical outcomes for patients. Compare the sentences in the following simple examples;

'Don't get the bandage wet'/ 'Keep the bandage dry'

'Try not to miss a dose'/ 'These pills work best when taken regularly'

Examining nurse-patient conversations could have important implications for nursing practice and nursing education. It suggests that improvements in the communication skills of nurses might be reflected in better patient care, better outcomes, and hence better results for the community as a whole.

Unfortunately, there are very many variables which contribute to clinical outcomes; the nurses, the patients, the health issues being attended to, and the environment in which the nursing is occurring. It quickly became apparent that separating out other variables so that the effects of language can be clearly seen would be beyond the scope of this thesis. That communication is difficult to measure or quantify only compounds the problem.

A different approach has therefore been taken: I have attempted to determine the common characteristics of the language used by examining the discourse of a small sample of expert nurses, in the expectation that these will represent desirable features and can be used to help define 'effective nursing language'. The thesis represents an appreciative enquiry in which I have sought to identify features of effective nurse-patient communication so that these can be reinforced.

\subsection{Thesis outline}

The thesis begins with a review of the literature relating to nurse-patient communication and examines communication in the workplace, contextual factors which have an impact on communication, attributes of an effective nurse communicator, some verbal strategies 
used by nurses and one particular and important study (Johnson, 1993) of expert nursepatient communication.

Literature from both linguistics and nursing contribute to an understanding of these aspects of communication, including the areas of small talk and relational practice. This leads into the literature describing techniques used in obtaining and analysing everyday conversations as they occur in the workplace.

In the methodology chapter, I give a brief description of ethnography and discourse analysis and the techniques used to record and analyse actual nurse-patient conversations. I also describe the study design and how consent was obtained from the nurses and patients involved.

Analysis of the recorded data is divided into three sections. The first (Chapter 4) gives an overview and some general impressions of the data. This section describes the explicit and implicit purposes of the conversations and general content. The second (Chapter 5) analyses the structure and content of the conversations, showing how they follow a pattern which consists of: establishing the agenda, eliciting information, doing a physical examination and developing a plan of care. The third section (Chapter 6) explores the linguistic repertoire of the nurses.

The thesis ends with discussion, recommendations and summary. 


\section{Chapter 2}

\section{Literature Review}

\subsection{Introduction}

This chapter explores the literature relevant to verbal nurse-patient communication, in order to place the study described in this thesis (examining actual nurse-patient conversations) in relation to what has already been written on the subject and in relation to current nursing practice.

I will examine studies of why communication between nurses and patients is important to the eventual therapeutic outcome and to the success of nursing care, before describing previous studies of various factors affecting nurse-patient interactions.

"Communication forms the foundation of all nursing care yet strangely, it is an area of nursing which has often been taken for granted or underestimated.” (Macleod-Clarke, 1984, p.52). Much has been written about communication in the health professions although often from a negative rather than a positive viewpoint. 
Because communication is difficult to measure or quantify it is hard to single out as a specific contributory factor in health outcomes. Rather, communication is more often noticed by its failure or absence.

Not surprisingly, these absences, failures and possible remedies are the focus of the majority of what has been written about communication in nursing and related professions ( Simpson, et al., 1991; Dickson, 1995; Heaven \& McGuire, 1996; Alexander, 2001).

This research study takes the form of an "appreciative enquiry", (Srivastva, Cooperrider and Associates, 1990; Hammond, 1996). Appreciative enquiry aims to identify and build on the positive aspects of what is being studied, which in this case is effective communication. I examine the linguistics literature on such communication and its characteristics, including the areas of small talk and relational practice. This leads into the literature describing techniques used in obtaining and analysing everyday conversations as they occur in the workplace, and lastly, a description of one particular study (Johnson, 1993) of expert nurse-patient communication. Johnson's study, like this one, sought to identify features of nurse-patient communication which might contribute to positive outcomes for patients. It was the only such study identified in the literature search.

\subsubsection{Communication in the workplace}

It is known that in the workplace and in many professional relationships the use of language is important (Tulin, 1997). However studies of language use within health settings have tended to focus on how language alienates patients through the use of jargon (technical terms specific to the profession) (Wodak, 1996), or how language is used to maintain power relationships (Coupland, Wiemann, \& Giles, 1991; Coupland, Coupland, \& Robinson, 1992; van Dijk, 1998). The studies of language use within nursing have followed this pattern, for example identifying ageism in the use of terms of address (Dobbin, 1990; Strong, 1985). The positive use of language, the role of language in ensuring effective communication, does not appear to have been examined in a nursing context. Although a significant proportion of nursing is embedded in what appears to be everyday conversation, these conversations have not come under scrutiny in terms of their usefulness for the nurse or patient. Thus, although effective communication is so important in this context, there is a gap in our knowledge of the characteristics of effective 
language and so, it might be supposed, in the evaluation of nursing skills and the education of nurses.

\subsection{The importance of communication in nursing}

Effective communication in nursing is important not only because accurate diagnosis and treatment depend on it but also because communication emerges as a significant factor in patient satisfaction surveys.

In a selective review of the literature on the patient's role in nurse-patient communication, Jarrett and Payne (1995) identified several factors which highlight the importance of communication. These were:

1. Nurses need good interviewing skills to enable accurate problem identification.

2. Attending to the patient as an individual rather than a collection of symptoms increases the importance of psychosocial factors (and hence communication) in nursing.

3. Research shows beneficial effects of giving information e.g. for increasing compliance with drug and treatment regimes or for reduction in stress, pain and anxiety.

4. Patient satisfaction surveys show that poor communication and lack of information are significant areas of complaint.

In addition to these four factors, I would add two more:

5. High quality nursing care (reflected in positive clinical outcomes) is characterised by effective communication (Kasch, 1986; Gunther \& Alligood, 2002).

6. Communication itself actually constitutes the care or nursing action in some instances (Mishler, 1984; Kasch, 1986; Parker \& Gardner, 1991; Candlin, 2000; Fenwick, Barclay \& Schmied, 2001). 


\subsubsection{Patient satisfaction and complaints}

The fourth point noted above by Jarrett and Payne (1995) relates to the importance of communication from the patient's perspective. The lack of effective communication is the single most common cause of complaint against health professionals (Fosbinder 1994; Jarrett \& Payne,1995; Macleod-Clarke, 1984; Simpson et al.,1991). The complaints are not always about a lack of information received; also style and method (by phone rather than face-to-face) and, sometimes, too much rather than too little information. In one study the shortcomings of style were glaringly obvious, "patients were interrupted by physicians so soon after they began describing their presenting problems (on average within 18 seconds) that they failed to disclose other significant concerns” (Simpson et al., 1991, p.1385).

When asked about their perceptions of nursing care, "patients almost exclusively described the nurses' interactive style .... not what task she was doing” (Fosbinder, 1994, p.1087). A similar comment is made in relation to doctor-patient interactions, "Most complaints by the public about physicians deal not with clinical competency problems, but with communication problems” (Simpson et al., 1991, p.1385). Even today, in our local District Health Board environment, communication problems seem to dominate the number of patient complaints (Black, 2002, personal communication).

\subsubsection{Beneficial effects of giving information}

Despite the danger of too much rather than too little information, there is a strong trend towards more sharing of information between health professionals and patients.

As Hinckley, Craig and Anderson (1990) point out “Advocates for patient consumerism have encouraged more active participation by patients and activities focused on encouraging question-asking have developed.” (p.524). The medical profession is clearly making an effort to meet the needs and demands of their patients but "Physicians generally overestimated patients' desire for decision-making and underestimated their desire for information” (p.527). This finding is reinforced by Simpson et al. (1991), who found that "Patient anxiety and dissatisfaction is related to uncertainty and lack of information, explanation, and feedback from the doctor.” (p.1385). This shows that doctors have 
recognized and responded to the desire by patients to be involved in decision-making but have not yet provided sufficient information on which patients can base their choice.

In many circumstances, giving information is not only beneficial but also essential. As a result of intense public comment around aspects of medical treatment and research in the mid-80s, The Report of The Cervical Cancer Inquiry (1988), otherwise known as the Cartwright inquiry, made particular mention of the need to keep patients informed. “The patient's consent is a pre-condition to all treatment or research [and therefore] she must have adequate information on which to base her decision.” (p.137). Discussing options for medical treatment in such a way that the patient is fully informed but not unduly alarmed or burdened is a skill in itself.

\subsubsection{Interviewing skills to identify patient concerns}

As mentioned previously, accurate diagnosis and treatment depend on effective communication and there are various techniques described in the literature. When facts are needed quickly, a question-answer style using closed questions is often effective and appropriate, but for many health situations a more exploratory and less direct approach is useful.

Mishler (1984) urges doctors to listen carefully to the patient's 'lifeworld' [their story] as the basis for understanding their experiences, interpretations and concerns. From this point the doctor is able to use the information to understand, diagnose and treat their problems. Simpson et al. (1991) agree. They write, "Physicians should encourage patients to discuss their main concerns without interruption or premature closure. This enhances satisfaction and efficacy of the consultation.” (p.1386). These authors introduce this idea with the reassurance that such an approach "contrary to the expectations of many doctors, this need not take long: a maximum of 2 1/2 minutes, or an average of 90 seconds” (ibid p.1386). This rather cold and calculated description of personal human interaction is complemented by the advice to “strive to elicit patients' perceptions of the illness and associated feelings and expectations” (ibid p.1386).

A conversational style of interview is advocated for nurses by Brown (1995), who explains the potential for such an approach to produce an accurate shared understanding of 
the client's health. An advantage of this approach, she explains, is that it is more clientfocused and less interpersonally controlling than the traditional question-answer format of many medical interviews. In a question-answer format, the doctor asking the questions is inclined to control many aspects of the conversation but particularly the topics, including what is explored or elaborated on and what is not. Such an approach limits the patient's ability to express their real concerns.

A very practical guide on how to conduct an interview for patient assessment is given by Haselfeld (1990). She advises, "Use the patient’s own words. Accurately summarize what the patient has said from time to time. This ensures understanding, demonstrates interest and encourages the patient to talk.” (p.557).

In their study involving 206 health professionals who were attending workshops on communication and counselling skills, Maguire, Faulkner, Booth, Elliot and Hillier (1996) describe specific questioning techniques which facilitate or inhibit disclosure of patient concerns.

Patient disclosure was promoted in several ways: by the use of open directive questions, e.g. 'How has chemotherapy been affecting you?'; by focusing and clarifying psychological aspects, e.g. 'You say you have been worrying. In what way?'; empathetic statements, summarizing, and making educated guesses, e.g. 'I get the feeling you have something else worrying you'.

Various approaches inhibited patient disclosure: the use of leading questions, e.g. 'You have taken chemotherapy in your stride haven't you?', or moving into advice and reassurance mode, e.g. 'I’m sure you will get better'.

Effective communication may have an effect on use of health services, recovery time and patient satisfaction. Tessler and Mechanic (1978, cited in Macleod Clark, (1984)) establish that individuals with unrecognized or unmet psychosocial needs are high users of health services and take longer to recover. Because psychosocial needs are identified and attended to largely through conversation, nurse-patient communication is an essential part of these needs being identified and met. 


\subsubsection{Collaboration in the nurse-patient relationship}

There is an increasing recognition that quality nursing care depends on establishing a collaborative nurse/patient relationship (Christensen, 1990; Johnson, 1993; Fenwick, Barclay \& Schmied, 2001; Gunther \& Alligood, 2002). Establishing such a relationship is achieved through effective communication. The connection between quality nursing care through the role of communication in building and maintaining relationships is explained: “ ... talk can be used as a strategic resource to establish, maintain repair and terminate relationships.” (Kasch, 1986, p.229). Thus the quality of nursing care is enhanced when nurses and patients can negotiate a mutually acceptable agreement on the goals of the encounter (Kasch, 1986).

Both the nurse and the patient perceive that the quality of care increases when the nurse pays attention to the patient's concerns, anticipates and meets needs, and informs the patient of the expected course of events. Gunther and Alligood (2002) give a slightly different emphasis "Individualised care necessitates knowing the patient so that the nurse can assist in applying information to that patient's unique life situation." (p.356) and elaborate by quoting Luker, Austin, Caress, and Hallett (2000), p.777: "Knowing the patient is an essential antecedent for the provision of good quality care". Hence, "Communication establishes the nurse-patient relationship that is directly linked to good nursing practice.” (Gunther \& Alligood, 2002, p.356)

It must be noted that while these views on the desirability of partnership or collaboration seem widely accepted, not all nurses agree. Waterworth and Luker (1990) ask whether some patients might be more concerned with pleasing the nurse than with participating in decisions regarding their care. In their view the nurse may unwittingly coerce patients into a collaborative role. Another challenge to the idea of collaboration comes from Candlin (2000 p.231) who explains “... patients (and some nurses too) frequently believe that in sickness people want to be 'cared for' and have the weight of decision-making taken from them.” I have sympathy with this view. However I would argue that both stances can be accommodated if the nurse provides the patient with an opportunity to participate and collaborate to the extent they wish and this is negotiated. 
Related to the activity of collaboration but not explored in depth here is the notion of coconstructed meaning. As Coupland (2000) explains, through talk there is a co-construction of meaning, a concordance or therapeutic alliance so that both parties (nurse and patient) can work together for an optimal outcome.

\subsubsection{Communication in itself can be therapeutic}

Several writers go further and state that communication not only affects or influences the perception of care but that the verbal interaction actually constitutes care or nursing action in some instances. "Discourse is viewed not as mere talk but as an essential and critical component of clinical practice” (Mishler, 1984, p8). Kasch (1986) reinforces this, arguing that the nurse/patient interaction is an important mode of nursing action and interpersonal goals are often synonymous with nursing objectives.

Parker and Gardner (1992) write, "Much of what nurses do in their everyday work is talk. They talk as they perform ongoing supportive, maintenance and restorative activities in delivering both technical and comforting care”.

At one point Mishler (1984) puts it simply as 'talk is work' and Parker and Gardner (1991) echo that 'work is talk'. This interesting symmetry is shown in the writing of Fenwick, Barclay and Schmied (2001) whose study in a neonatal unit revealed that the relationship between nurses and mothers is both the context and the method by which nursing care is delivered. It was in their collaborative relationship with the nurses that the mothers felt able to explore issues of concern and the nurses were able to share knowledge and expertise. Their everyday conversations were mutually beneficial.

\subsection{Contextual factors affecting communication in the nurse/patient relationship}

Contextual factors affecting communication can include issues relating to the setting, the participants and the nature of the health issues at the heart of the encounter. The attributes of the nurse are also affected by context, but are best discussed separately in a later section. 


\subsubsection{Setting in time and place}

District nurses work with individuals and families, predominantly in the patient's own home (as opposed to a hospital or clinic). It is a free service but the nurse does not have free statutory right of access to the patients' homes. Initial contact and continued access must be negotiated at the outset. Hunt (1991) notes the potential difficulty posed by the setting: "The district nurse fulfils two potentially conflicting roles; she is at once a guest in the home and skilled professional. She must be enough of the guest to enable relatives or patients to maintain the feeling that they are still master or mistress of their own home, but she must also exert sufficient influence to establish her own authority.” (Hunt 1991 p.936). A study of how health visitors accomplish the challenge of gaining access to clients sheds light on this process (Luker \& Chalmers, 1990). Their study suggests that the work involves many strategies to ensure entry and re-entry.

As well as physical access the nurse must establish some kind of rapport or relationship with the patient and family in order for them to begin working together. And unlike hospital (ward) nurses, the district nurse frequently enters such a relationship expecting it to extend for weeks, months, or even years. When there is this expectation of prolonged engagement there is added incentive for all participants to build harmonious and effective patterns of communication. It is remarkable that there is little written on this aspect of nursing practice given that more and more health care is being conducted in patients' homes rather than in hospital.

In writing about doctor-patient communication Ainsworth-Vaughn (1998 p.103) states "Long-term physician-patient relationships have their own kind of intimacy, created both by talk about intimate matters and by repeated interaction over the passage of time. Even when the encounter was an initial one, the participants could project their relationship indefinitely far into the future."

Christensen (1990) also alludes to repeated interactions, referring to them as 'episodic continuity' where there is intermittent contact over time although she is not specifically referring to nursing communication in this context.

West (1995, p.112) notes "conversational behaviours at one point in time will have consequences for any subsequent turns at another”. This is really making the obvious point 
that not only is the length of the relationship relevant but the nature of each conversation affects those that follow.

The data in this present study support the suggestion that expert nurses enter a professional relationship mindful of the possibility that it will have a long duration, and mindful of the impact and consequences of early conversations.

\subsubsection{Knowing the patient}

The extent to which a patient and nurse know each other influences the nature of their communication. There are differences in first rather than subsequent visits. First visits or contacts tend to be more formal until each participant 'gets the measure' of the other. Hinckley, Craig and Anderson, (1990) describe the process of mutual evaluation thus “...the role of stereotypes may be magnified in a first encounter due to the need for each to evaluate the other based on very little information. As the relationship develops, stereotypical responses decrease.” Sociolinguists (Holmes, 1992) have identified social dimensions which influence language choice such as social distance, status and the formality of the setting. Nurses, (Hinckley, Craig \& Anderson, 1990) comment on how factors such as anxiety on the part of the patient have an impact on the nature of nursepatient communication. As nurse and patient get to know each other they gain insights into the roles and expectations of each other and the nature of their communication changes. The speed of this process depends on many variables including gender, age, status, and the educational level of both participants.

Surprisingly, Mishler (1984 p.60) describes it thus "... patients and physicians talk to each other in ways that we as members of the same culture recognize as contextually appropriate. ... Our sense of appropriateness depends on shared and tacit understandings on commonly held and often implicit assumptions of how to ... talk and of what to talk about in this situation". Although this is an accurate account in most instances, there are many occasions in district nursing and no doubt in other settings where we are not members of the same culture and there are relatively few shared, tacit or commonly held assumptions on which conversation can be based. For example, discussing a diagnosis of cancer is handled very differently depending on the culture of the patient and the presence 
or absence of family members. And it is these situations which most challenge our ability to communicate effectively.

In their study of provider-patient information exchanges, Hinckley, Craig and Anderson (1990) explain that merely naming someone a patient can subtly attach dependence and anxiety to that person. Until the stereotyped 'patient' becomes a known 'individual' there is likely to be formal detached communication. To counteract this distance the nurse typically engages in conversation in an attempt to understand each patient's situation and outlook on life. In describing this activity, Bjornsdottir (1998) notes that such talk which she calls "the private discourses of nursing" was much more engaged than the "public discourses" for example when nurses were documenting care or handing over to the next shift. By 'engaged' I assume she means that it was more solicitous, personal and direct. Bottorf, Steele, Davies, Porterfield, Garossino and Shaw (2000) explain the importance of getting to know the patient as a basis for supporting patient choice. The nurses in their study of facilitating decision making in palliative care, believed that they needed to know their patients in order to offer appropriate choices and to understand the factors which patients considered in making choices. The nurses also realised that "patients needed to feel comfortable before they could discuss the hesitations, concerns, and practical issues they took into consideration in making choices. Nurses spent considerable time and energy getting to know their patients, using open-ended rather than leading questions, observing the patient's behaviour, taking advantage of the time it took to complete nursing tasks to talk to patients about their needs and desires, checking to determine patient preferences and obtaining relevant information from family and other staff.” (p144).

Despite all the arguments in favour of nurses getting to know patients, there are times when the attempts by nurses to know the patient have been inappropriate and possibly unwelcome. As May (1992) states, “ ... the most trivial or routine encounters were characterised as opportunities to formulate 'relationships' ". Clearly the usefulness of the endeavour relates in some measure to the expected length of engagement between nurse and patient and the nature of the health issues involved. 


\subsubsection{Nature of the health issues}

In a study of the style of conversations that registered nurses used with elderly residents during activities of morning care (Gibb \& O’Brien, 1990), the authors discovered that conversations varied consistently in relation to the physical procedure being performed. Activities such as showering and dressing provided opportunity for social chat. These findings were discussed in terms of how these regular nursing activities served to meet psychological needs of the residents as addressed through verbal interaction.

In contrast to caring for elderly residents, the challenges associated with nursing terminally ill patients demand different conversational skills of a nurse. Hunt (1991) describes occasions where nurses avoid or block the discussion of certain topics. This is usually when the nurse is inadequately prepared, or has a fear of death, or anxiety about upsetting the patient. The attributes of an effective nurse communicator will be discussed in the next section.

Sometimes the whole situation is so complex that clear communication is hard to achieve. Dickson (1995) notes,

"The complexities of problems faced often militate against the successful sharing of messages without ambiguity and information loss. Nurse, patient and family may have different meanings for the same word for example the word 'chronic' or may differ in the concepts, language and knowledge base with which they respectively make sense of these matters." (p.77).

Along with different meanings, the participants may also have different expectations. District nurses are frequently in a situation where a patient asks for complete honesty about their condition while the family, present in the room, have made it clear that they do not want any unpleasant or adverse aspects discussed. Giving accurate information while maintaining hope and morale is one of the challenges faced by health professionals. Later, in the analysis chapters, there are illustrations from the data in this study of how this is done for example in Chapter 4 example 4.5 and in Chapter 5 example 5.9. 


\subsection{Attributes of an effective nurse communicator}

A number of writers discuss, either directly or indirectly, the attributes of an effective nurse communicator. Most of the attributes mentioned can be allocated to one of three categories

- a repertoire of communicative skills,

- a professional philosophy,

- maturity.

The verbal skills nurses need are described by Macleod Clark (1984) as " a repertoire of interaction techniques, observing and listening, reinforcing and encouraging, questioning, responding, and giving information.” (p.55). She elaborates on specific questioning techniques, for instance using closed and open questions. "Closed questions can be useful when it is necessary to collect facts quickly. They can also focus the conversation but, when used habitually, can act as an inhibiting force on the development of the interaction.” (p.56). Norton and Talerico (2000) talk about 'communication strategies' for example being clear, avoiding euphemisms, spelling out the goals and expectations of treatment and being specific when using words such as 'hope' and 'better'.

On the other hand, 'being clear' is not always a requirement for effective communication. Vague, ambiguous or woolly language has definite usefulness in particular situations for example in diplomatic politeness or in moderating a sea of precision (Channell, 1994). An example of the latter might be in a description of how steroids work. To say that steroids provide a general sense of well-being is often more helpful than a detailed description of steroid physiology. Vague, ambiguous language is evident in the data of this study.

Ambiguity is a feature associated with the multiple goals of much professional activity (Coupland, 2000). In their classic work entitled “How are you?":Negotiating phatic communion Coupland, Coupland and Robinson (1992) analyse responses to this question when posed to elderly people at the outset of interviews about their medical experiences. Asking "How are you?" in a medical context allows the patient to respond with social chat or medical information. The ambiguity attached to the question in this setting is very useful in allowing the patient to choose the topic of conversation, as is noted throughout the data in this research and discussed further in the analysis chapter. 
So we find that, paradoxically, the repertoire of communicative skills includes use of clarity and ambiguity and open and closed questions. Some guidance on when and how to make use of this repertoire is given in a body of literature on how to acquire communicative skills. Haselfeld (1990) for example, gives a very practical guide to conducting an effective interview for patient assessment. In a study of how nurses can help cancer patients to disclose their concerns, Maguire, Faulkner, Booth, Elliot and Hillier (1996) give examples of the types of clinical questions which inhibit or enhance disclosure.

A way of measuring communication skills for health professionals, particularly nurses involved in cancer care, and suggesting ways of teaching communication skills was offered by Booth, Maguire and Hillier (1999). Lore (1981) advocates the use of individual and group activities to practice and discover communicative styles.

Having a clear professional philosophy or a set of beliefs and attitudes that underpin their practice is seen as important by several authors. Nurses' attitudes and values (for example toward patient autonomy) and their ability to be flexible, innovative and willing to entertain multiple possibilities all have an impact on communication and patient care (Bottorf, Steele, Davies, Porterfield, Garossino \& Shaw, 2000). These authors also describe the positive effects of the nurse making patient-centred choices and sustaining the patient's sense of integrity and worth. Edwards and Brilhart (1981) summarise the attributes of therapeutic nurse communicators as having a degree of openness, an acceptance of others and a desire to achieve mutual understanding.

Related to the concept of having a clear professional philosophy is the idea of personal maturity, practice wisdom, or an ability and habit of critically reflecting on practice. Selfawareness is a quality attached to effective nurse communicators and is mentioned by Lore (1981) and Parle, Maguire and Heaven (1997)

Florence Nightingale (1860) sets out plainly her strong views on how to communicate with the sick in a chapter entitled Chattering Hopes and Advices:

"I would appeal most seriously to all friends, visitors, and attendants of the sick to leave off this practice of attempting to 'cheer' the sick by making light of their danger and by exaggerating their probabilities of recovery.” (p.96). 
She also gives examples of what is especially unhelpful for example 'absurd consolations' and the 'wonderful presumption of the advisers of the sick' who

"advised [me] to go to every place in and out of England _ to take every kind of exercise in existence [and] to imbibe every different kind of stimulus that has ever been invented.” (p.96).

Even the best nurse communicators need support in order to be effective. Parle, Maguire and Heaven (1997) explain that lack of support in the workplace is more likely to lead to distancing tactics. Practical measures are necessary such as having ample time and psychological support especially when breaking bad news or dealing with an angry patient.

Along with her repertoire of skills, professional philosophy, and a degree of maturity, the effective nurse communicator has at her disposal some broader communication strategies. These include relational practice, small talk and what I call translating, blending and accommodating in conversation.

\subsection{Communication strategies}

\subsubsection{Relational practice}

The concept of relational practice as defined by Fletcher (1999) is a fundamental part of the analysis described later in this thesis. In discussing relational practice in an engineering firm, Fletcher (1999) says it includes all those "off-line, backstage or collaborative” activities that support others and go largely unrecognised and unrewarded. Fletcher’s findings resonate strongly with my experience of nursing.

In a nursing context, relational practice is the work that goes in to building the relationship between carers and the patient. It is easy to overlook the significance of relational practice in a medical world which focuses on physically observable biological processes. However, unlike medicine, nursing concerns itself primarily with a person's response and adaptation to disease or injury. 
Relational practice is crucial to achieving the purpose of district nursing and will be explored further in section 4.6.

One of the ways relational practice occurs is through small talk.

\subsubsection{Small talk}

Small talk fulfils many functions, some of which seem contradictory. For example small talk enables speakers to approach or avoid discussion of more serious topics. Small talk can put people at ease or cause annoyance and irritation. In their study of chatting in a neonatal nursery, Fenwick, Barclay and Schmied (2001) explored the use of chat and social talk as a clinical tool. They noted that there were many beneficial aspects of chat or small talk which came from minimising the power differential between nurses and mothers and building and maintaining a trusting relationship in which concerns and information were shared. On the other hand, these researchers also pointed out the detrimental effect of 'bad' chat described as off-the-cuff joking, banter, superficial, and 'dismissive' remarks which could cause distress. Clearly there is skill in knowing when and how to use small talk and what kind to use.

Bjornsdottir (2001) explains that it takes time for a nurse to know and understand a patient's situation or point of view and this frequently happens through chatting. Similarly, Vancott (1989) describes how patients reveal their concerns in long narrative discourse where social talk or small talk is woven in amongst medical talk and is vital to the unfolding history.

Sociolinguists point out that small talk has variously been described as formulaic, peripheral, minor, unimportant, but note that it might be better described as off-topic chat not concerned with the explicit purpose for which the speakers are together (Coupland, 2000). Nevertheless, Holmes (2000) demonstrates that small talk can serve a pivotal role in the workplace by furthering interpersonal and sometimes transactional goals. 


\subsubsection{Translating, blending and accommodating in conversation}

Translating, blending and accommodating are three linguistic strategies used by nurses to build rapport and promote effective communication between themselves and patients and other health professionals.

Fosbinder (1994 p.1087) describes translating as “... the process of interpreting to the patient significant phenomena related to the hospital environment, and information related to their condition”. Her definition generously includes activities such as informing, explaining, instructing and teaching.

Several authors refer to the need to translate medical language into everyday language (Mishler 1984; Bourhis, Roth \& MacQueen 1989; Fosbinder 1994; Dickson 1995; Castledine 2002). According to Bourhis, Roth and MacQueen (1989), nurses 'translate' from medical language into everyday language in order to render it more comprehensible to patients. This view is not only reinforced by Castledine (2002) but he adds a plea that such an activity be given greater emphasis in nursing and medical education.

Mishler (1984) writes at length about medical language and everyday language in terms of the 'voice of medicine and the voice of the lifeworld'. He comments that "...humane care refers to the primacy accorded to the patients' lifeworld ....as the basis for understanding, diagnosing and treating their problems.” (p.192). In saying this, Mishler acknowledges the need for the medical profession to listen carefully to the words used by patients and then to choose language on the basis of what the patient will find easiest to assimilate and understand. So, in this case, the translating is happening in the doctor's mind before speaking to the patient.

Another strategy mentioned in the literature and clearly evident throughout the data in this study was that of blending. Blending in conversation occurs when social talk is mixed with medical talk.

Blending occurs haphazardly for example when patients disclose their concerns in long narrative discourse (Vancott, 1989) and deliberately for example when nurses move out of medical talk into social talk in the middle of an intrusive procedure to reduce awkwardness or embarrassment. 
In their detailed analysis of negotiation in doctor-elderly patient consultations, Coupland, Robinson and Coupland (1994) show how social and medical talk are blended in complex discourse patterns. They suggest that this blending may have special salience in contexts, such as geriatrics, where holistic care has an explicit priority. This is because they realise that social factors have such an impact on health outcomes particularly for the elderly. I wholeheartedly agree with their final conclusion that an ideology which places "the medical in the context of the social is difficult to resist as an ideal of all medical [nursing] practice”. Such a stance acknowledges the individuality of patient responses to illness and the impact of context on health issues.

Accommodation is both a strategy and a theory of communication (Street, 1991). The theory is that when people wish to establish rapport, win approval, affiliate, identify socially or communicate effectively they will adjust their communicative style towards the style of the person they are talking to. This convergent accommodation is reflected at many levels including changes in speech rate, vocal intensity, language switches and accent switches (Bourhis, Roth \& MacQueen, 1989). When speakers fail or decide not to adapt their patterns of speech, complementary or divergent accommodation occurs (Street, 1991). According to Street (1991), complementarity occurs when speakers mutually attempt to maintain their social differences communicatively. Divergence occurs when a speaker deliberately differentiates their communicative style from that of the person they are speaking with. This may have the effect of distancing themselves socially or rendering the other person less powerful or enticing the other speaker to change their style. Accommodation is noted in the data of this study and will be referred to in the analysis. 


\subsection{Appreciative enquiry; a study of expert nurse-patient communication}

As mentioned in the introduction to this chapter, appreciative enquiry aims to identify and build on the positive aspects of what is being studied.

In this final section I will describe in detail one particular study of nurse-patient communication (Johnson, 1993) which takes the form of an appreciative enquiry. Its purpose was very similar to the aims of this study and many of its features will be referred to later in this thesis.

The purpose of Johnson's study was to uncover a process that might contribute to understanding the positive outcomes of nurse practitioner care. The particular focus of her study was a desire to discover if there were

- differences between nurses and doctors in their communication strategies with patients and

- whether any differences could be explained by differences in health care ideology between nursing and medicine

Twenty-four taped nurse-patient conversations, field notes from observations, and taped interviews between the researcher and the nurse-participants constituted the data for the study. The nurse participants in Johnson's study were white, female, in their mid-30s to mid-40s, two held master's degrees, one held a bachelor's degree and all were Nurse Practitioners.

Johnson analysed her data using a combination of ethnographic and discourse analysis. She organised the material in each conversation into four major activities of the clinic visit: establishing the agenda, eliciting information from the patient, conducting a physical examination and developing a plan of care.

The findings of the study show that several factors contribute to successful Nurse Practitioner-Patient outcomes. These factors related to the particular qualities of the nurses and the importance they placed on attending to the patient's perspective.

Johnson suggests that the nurses had nursing education, experience, self-awareness and personal confidence that made them skilled in developing rapport with patients; that they 
saw their relationship with the patient as central to the process of delivering care and had a clear patient focus. They attended to the patient's 'lifeworld', diverting from the "strictly medical to the perceived concern of the patient, by use of a shared language with patients, by a stance of partnership and by turns in conversation that establish a connectedness...” (Johnson, 1993 p.156). In terms of their contribution to the health organisation, the nurses saw their main contribution as coordination, continuity and advocacy.

Johnson concludes by hoping that her research will stimulate nurses to critically reflect on whether or not the beliefs that form the basis of their practice are being actualised. Her study is important because she identifies some of the features of effective nurse-patient communication using actual fragments of conversation as evidence. I found similar evidence in my data.

\subsection{Summary and conclusions}

Effective communication is important for patients, nurses and the positive outcomes of health care. Contextual factors influence nurse-patient communication, in particular; the nature of the health issues under discussion, the setting and whether the speakers are known to each other. In some circumstances, communication actually constitutes nursing care.

Attributes of an effective nurse communicator include having a professional philosophy, a repertoire of communicative skills and maturity. Above all, a style which conveys friendly serious concern is what patients find to be highly desirable and effective.

The desired repertoire of communicative skills or strategies includes an appreciation of the value of relational practice, an ability to use small talk to advantage and an ability to translate between the world of medicine and the everyday world or 'lifeworld'.

Much of what is written about nurse-patient and doctor-patient communication focuses on the failures or shortcomings of this activity and what might or should be done to remedy the situation. The literature is sporadic with little evidence of dialogue, development or comparisons between studies. 
This study seeks to take a more positive approach by identifying the actual features of expert nurse-patient communication. 


\section{Chapter 3:}

\section{Methodology}

\subsection{Introduction}

This chapter describes how the study of effective communication in a district nursing setting was planned, how the data was gathered and how it was analysed.

At the time of the study I was working as a clinical nurse specialist in a district nursing service. In this role I was nursing in a domiciliary setting and had responsibility for the practice and performance of other nurses doing the same. A desire to use linguistic analysis to reveal expert nursing practice in the 'everyday' conversations between nurses and patients was the starting point for this study. I wanted to involve colleagues in the process because we shared an interest in fostering a climate of research in our workplace. Furthermore I wanted this research to be in the nature of 'appreciative enquiry' which meant identifying and building on positive aspects of district nursing.

Using a method developed by the Language in the Workplace Project, (Stubbe, 1998) two nurse participants recorded a small sample of their conversations with patients as they occurred naturally in clinical practice. 
These conversations constitute the main body of raw data for the study. The data was analysed using a combination of discourse and ethnographic analysis.

\subsection{Selection of Method}

Because little is known about the positive rather than negative impact of nurses’ language on practice, a qualitative and exploratory approach was appropriate. Language only has meaning in context. It follows that in order to explore the language of district nurses it was necessary to "get into" that world. I looked for a method of qualitative enquiry which included myself as the researcher in a subjective role.

One of the challenges was to obtain data consisting of genuine, naturally occurring conversations while at the same time attending to ethical concerns of privacy and confidentiality and the existing relationship of trust between nurse and patient.

When it came to analysis of the data, insider knowledge of the context helped to uncover the richness of meaning in the conversations and the subtle interconnections and nuances easily missed by an outside observer.

Drawing on the interest and experience of the Language in the Workplace Project (LWP) enabled me to confidently adapt their methodology (Stubbe, 1998) whereby nurse participants recorded conversations as they occurred in clinical practice. I see the method as a refinement of an ethnographic approach, which I will now go on to, describe.

\subsubsection{Ethnographic study}

Ethnography is a qualitative method of inquiry involving a process of observing documenting and analysing patterns of naturally occurring behaviour. It is a form of research which relies on first hand knowledge of social processes to convey the reality of someone else’s world (Mackenzie, 1994).

Although ethnography arose from the field of anthropology where the concern was to 'grasp the native's point of view', ethnography is equally appropriate for researching other groups including occupational groups such as district nurses. 
While the goals of ethnography are, at least in the first instance, descriptive the potential significance goes far beyond a mere cataloguing of facts (Saville-Troike, 1982). The starting point is a set of questions from which fieldwork is planned. The researcher becomes a participant in the field of study, deliberately cultivating an understanding and appreciation of the 'insider's' view in order to explain the phenomena observed.

Ethnography builds a portrait of people, making explicit their identities and interests as well as the nature and terms of their transactions (Dill, 1995). The goal is to understand meaning rather than truth in specific situations. Ethnography can be done on a large or small scale.

Gathering ethnographic data is frequently achieved by identifying key participants or informants and tape-recording semi structured interviews (Dill, 1995; Barton, Smith, Brown, \& Supples, 1993; Morton \& Mackenzie, 1994). Other methods are participant observation, field observation and examination of documents (Holland, 1993; Dill, 1995). The interview is the most important data collection tool for ethnography. It is a series of friendly conversations with a clear research agenda.

One of the major advantages of the ethnographic method is that the researcher can use themselves as a source of information and interpretation.

Ongoing analysis takes place as the fieldwork progresses and leads to the development of hypotheses and testing of these through further fieldwork and data collection. In this respect ethnography has much in common with grounded theory. As analysis proceeds "subtle interconnections of meaning (can be identified) that an outsider would attain only with difficulty if at all” (Saville-Troike, 1982 p.110).

Madeleine Leininger is a nurse anthropologist who has written extensively on this method of research and subsequent formation of nursing theory and practice. Her works, published in the 1970s , set out a description of 'culture care' (Leininger 1970, 1978, 1991), later developed as 'transcultural nursing' (Leininger, 1996). 'Culture care' is a way of nursing which provides "culturally congruent and meaningful care for health and well-being” (Leininger, 2001). So pervasive are her ideas and approaches in parts of the United States that there is now the term 'ethnonursing'. Nevertheless, Leininger has critics within the nursing world who claim that her approach focuses too heavily on ethnicity and fails to 
give adequate consideration to variables such as gender, class, political or historical context (Bruni, 1988; Swendson \& Windsor, 1996). Her severest critics claim that ethnonursing perpetuates practice which is paternalistic and ethnocentric, allowing nurses to define others as distinct racial groups with defined sets of physical and behavioural characteristics rather than as individuals with individual needs and preferences (Swendson \& Windsor, 1996). These are claims which Leininger vehemently refutes (Leininger, 1996).

While that argument continues, it is not the method of ethnography which is in dispute but rather Leininger's subsequent espoused approach to nursing and nursing education.

In this study I have adapted the ethnographic method. Rather than interviewing key informants about their work, the key informants provided raw data directly by recording their conversations as they occurred in clinical practice. This technique proved a simple and successful way of gathering data and it had the added advantage of avoiding a mediating process which happens when interviewing key informants. Because of this 'stand alone' quality of the data it also allows a researcher the luxury of considering and testing various approaches to analysis. 


\subsubsection{The Language in the Workplace methodology}

The Language in the Workplace Project (LWP) was begun in 1996 with the aims (Stubbe, 1998) of:

1) analysing features of effective interpersonal communication in a variety of workplaces from a sociolinguistic perspective and,

2) exploring practical implications of the findings.

The aims of my study closely matched those of the project and it seemed logical to use the methodology so successfully employed already by the LWP.

The LWP methodology involved having participants wear lapel microphones and record their conversations as they occurred in clinical practice.

Rather than identifying and interviewing key informants, data was gathered by participants themselves who wore lapel microphones and recorded their conversations as they worked. During and after the data collection, participants were free to edit and delete material as they wished. This method gave participants more control over data collection and was less intrusive than having a researcher present. None of the participants in my study chose to edit or delete any material.

\subsubsection{Discourse Analysis}

Discourse analysis is a process that can "help us explain the relationship between what we say and what we mean, and understand, in a particular context” (Paltridge, 2000 p.3).

Within discourse analysis there are currently many approaches some of which I will describe briefly.

At one end of the spectrum are the approaches such as speech act theory, conversation analysis and pragmatics which concentrate on linguistic construction and at the other end of the spectrum lies critical discourse analysis which has much more of a political interpretive focus. The variations in approach reflect different emphases given to the actual words and the context and the outcome. Speech act theory, for example, describes how we use language to do things such as requesting, giving orders, and giving warnings. 
Pragmatics gives heavy emphasis to what the speaker is meaning and the rules which guide our interpretation of the literal meaning (conversational maxims).

Discourse analysis takes text and incorporates contextual factors to help us understand particular language choices.

“...we situate a sentence within a conversation within a relationship within a history within a location.... In some cases there are a variety of ways in which a hearer could interpret an utterance. How do hearers (and analysts) decide which interpretation is most likely? ...[They] attend to both the nature and number of contextual features supporting an interpretation” (Ainsworth-Vaughan, 1998 p.9).

These definitions rest on the assumption that language and society are constantly changing so that a piece of text can only be interpreted in relation to a specific time and context.

Discourse analysis attempts to explain the connection between what is said and what is meant in naturally occurring language. One way of approaching discourse analysis is to look at how the text flows from speaker to speaker and topic to topic, then look at the content of the text, and thirdly the way in which relationships between the speakers are expressed in the text. These three features, called textual, ideational and interpersonal, are used by Mishler (1984) in his extensive study of the discourse used in doctor-patient interactions. This approach has influenced the way I went about the analysis of the data in this study.

The following sections describe how the research study was implemented.

\subsection{Study Design}

\subsubsection{Preparatory work and pilot study}

In preparing for the research, I had a discussion of the proposed study with colleagues in the district nursing service. I needed to gauge their interest in participating and get a sense of how they might perceive the relevance and value of the research. It was also an 
opportunity for us to consider any obstacles or practical issues to be resolved. To succeed their support was essential and happily they were interested and encouraging.

I formalised links with the Language in the Workplace Project (LWP) at Victoria University. The LWP team had collected data from several government departments, factories and private industry and wanted to gather data from nurses. They had already developed a methodology for recording conversations in the workplace.

Valuable preparatory work included a day with an experienced linguist researcher. She made two domiciliary visits with me and identified technical issues to be considered during data collection for example making sure there was no radio on in the background.

An application was made to the Wellington Ethics Committee for approval for the research.

Once ethical approval was granted, the project was again discussed with colleagues, this time in more detail, and interested potential participants were given information sheets and consent forms to take away and consider. (See the Appendices for copies of these forms.)

In preparation, I carried out a pilot study which consisted of gaining consent and recording one interaction between a patient and myself in a domiciliary setting in the course of regular district nursing work. The pilot study achieved the following. It:

- identified steps necessary to ensure good quality sound recording was made;

- explored the willingness of patients to participate;

- identified a process which allowed normal nursing practice to continue at the same time as data collection;

- demonstrated that self consciousness lasted only as long as the opening exchanges.

The most important lesson learned was the need to be completely familiar with the recorder. Time spent doing this was well rewarded. It took time to become familiar with the equipment and I probably underestimated this. Several early attempts at recording were unsuccessful when the recorder was inadvertently switched off while being tucked into a pocket. 


\subsubsection{Ethical considerations}

The main ethical concerns in relation to this study were that:

- $\quad$ the research be conducted in a conscientious manner;

- all participants agree to participate freely and voluntarily, understanding that they could withdraw at any stage without prejudice to any future care or employment;

- $\quad$ a written information sheet was given to all participants; See Appendix 1

- written consent was obtained only after sufficient time had passed to enable a considered and unhurried decision; See Appendix 2

- $\quad$ no-one other than the researcher and transcriber had access to raw data; and

- $\quad$ written reports contain no information which may identify participants.

The pilot project failed to prepare me for the problems raised by inadvertent recording of people without their knowledge. This will be addressed later in Chapter 3.7.

\subsubsection{Authenticity and rigour}

The most obvious threat to validity when using this methodology is the degree to which recorded conversations represent those which take place in everyday practice. In other words, how authentic were the conversations and did the presence of the recorder alter the interaction?

This threat is sometimes called the observer's paradox. “The observer cannot observe [hear] what would have happened if she had not been present” (Saville-Troike, 1982 p.113). It is the phenomenon where the quality of data is affected by the data collection process itself. The presence of recording equipment and the process of gaining consent mean that there is a heightened awareness of 'being observed' and this may alter the nature of the conversation.

Several strategies were used to reduce the potential effect of the observer's paradox. 
These were:

- $\quad$ selecting patients who had met the nurse on at least two previous occasions so that they already had some kind of rapport which would aid in recording a natural exchange;

- $\quad$ use of discreet recording equipment worn or placed unobtrusively;

- self-recording so there was no need for a third party to be present with the sole purpose of data gathering; and

- use of natural situations in a familiar setting rather than staged, reconstructed or formalised interviews. Recordings were made in the course of everyday work rather than at a time specifically arranged for data gathering.

Qualitative methodologies build in mechanisms to strengthen rigour. Within this study, these included:

- choosing key informants or participants who were able to communicate insider knowledge. The two nurse participants were both expert nurses who had worked in their role as experts for a number of years. As well as their clinical work, both nurses had some teaching responsibilities and so they could easily articulate the nature and context of their work;

- documenting evidence for interpretation of findings. This will be described in chapters 4, 5 and 6;

- making explicit the researcher's role in the field and her relationship with the participants as explained in the introduction; and

- $\quad$ checking inferences with participants.

\subsubsection{Setting}

The study was conducted in the District Nursing Service of Capital Coast Health, now Capital and Coast District Health Board, (CC DHB) in Wellington city. CC DHB is the major government-funded public (ie non fee paying) health provider of primary, 
secondary, and tertiary health care in this city. District nurses are part of the public health system and they work primarily in the patient's own home. District nurses provide 24 hour professional nursing including generalist and specialist areas of practice. Typically, a district nurse will start her day at the office then make 6 to 8 domiciliary visits and return to the office to write notes, liase with other health professionals and prepare equipment and supplies for the following day.

Data was collected in patients' homes in the course of regular district nursing visits. The nature of each domiciliary visit varies depending on many factors. To a greater or lesser degree the nurse assesses how the patient and family are coping with their health issues and she provides physical care, information and support. Where possible and appropriate she includes family members in the process and encourages efforts towards their independence. In some situations district nurses have an ongoing professional relationship with patients which lasts for years due to the chronic or severe nature of the patient's medical condition. In such cases it is especially important to establish and maintain a positive relationship.

\subsubsection{Participants}

While this study focuses primarily on the nurses, there were three groups of participants: 2 nurses, 6 patients and 3 other people who were relatives of the patients. I will describe the characteristics of these groups and how they were selected. There was no attempt in this exploratory study to obtain an ethnic, gender or social balance in either the nurse or patient groups.

The recorded conversations involve six different patients and in one instance the same patient on two occasions. The characteristics of the patients are given in Table 1 (overleaf). 
Table 1: Characteristics of the patients participating in the study.

\begin{tabular}{llll}
\hline Patient id & Gender & Ethnicity & Age (years) \\
\hline DN01-01a/b & F & Pakeha & $25-29$ \\
DN01-02 & F & Pakeha & $50-54$ \\
DN02-01 & F & Pakeha & $65-69$ \\
DN02-03 & F & Samoan & $60-64$ \\
DN02-02 & M & Pakeha & $70-74$ \\
DN02-04 & $M$ & Indian & $75-79$ \\
\hline
\end{tabular}

As well as the nurses and patients there were other people who became participants in the study. This occurred inadvertently in three of the conversations. In two cases it was the patient's spouse and in the third it was the patient's daughter. None were present for the entire interaction and their contributions to the conversations were very brief. On all three occasions the nurse participant alerted the person to the fact the conversation was being recorded and verbal consent was given.

\subsubsection{How the participants were selected}

The process was to recruit nurses to the study first and then the selection of patients followed.

In selecting nurse participants, there were some important considerations.

They needed to be identified as expert practitioners, able to participate or withdraw without any prejudice to our working relationship, and preferably be easily accessible to me as a researcher.

Nursing expertise is officially recognised at CCH by a clinical career pathway which ranks nurses from newly qualified RN1(Registered Nurse 1) to RNIV (Registered Nurse IV) and beyond this to Nurse Specialist. The $\mathrm{CCH}$ clinical career pathway has been developed using the work of Benner (1984) as its basis. Progression on the clinical career pathway is dependant on each nurse's ability to demonstrate competencies and attributes associated with each level rather than simply length of experience. The majority of the nursing workforce is at the level of RNII. Therefore my target group of experts included all nurses 
on the career pathway above and including RN III. However, to exclude or avoid any sense of coercion or obligation which may have arisen in the group over whom I had overview, I had to limit the target group further and restrict it to nurse specialists.

Nurse participants from the target group of nurse specialists were invited to volunteer to participate. There were eight potential nurse participants, six of them working from the same office building as myself.

The first two nurses to volunteer were selected.

The nurse participants were both Nurse Specialists, female, Pakeha, between 45 and 55 years old, each with more than 20 years experience of nursing.

The 6 patients were drawn from the existing caseloads of the participating nurses by the nurses themselves. The ability of the nurses to select the patients was an important feature of the methodology and contributed to the collection of authentic data.

Because the nurses and patients already knew each other and were continuing an established relationship, their conversations were more likely to be a true representation of workplace conversations. It reduced the chances of a staged or stilted conversation, which may have occurred if separately recruited nurses and patients were put together for the purpose of the research. Potential participants in the patient group were those who:

- $\quad$ had met the nurse on at least two occasions

- $\quad$ spoke English

- $\quad$ were able to give written informed consent

From this pool, patients were excluded from the study who:

- $\quad$ in the nurse’s view, may have found the request for participation stressful.

\subsection{Obtaining consent from participants:}

The nurses volunteered to participate and informally discussed with me what was involved. They took information sheets and consent forms (Appendices 1 and 2) and came back to me in their own time. This took several weeks. 
When the nurses were ready to collect data they approached patients on their caseload and invited them to participate. If the patients were interested, the nurse would leave an information sheet and a consent form, (Appendices 1 and 2) allowing a few days for the patients to consider whether to go ahead and participate. Prior to her next visit the nurse would phone the patient to see whether they had agreed and if so she would take the recording equipment.

The same information sheets and consent forms were used for nurses and for patients.

\subsection{Data collection}

\subsubsection{Amount of Data}

In total, 2 hours, 35 minutes and 15 seconds of recorded interaction was collected and transcribed.

Table 2. Length of recorded conversations

\begin{tabular}{lll}
\hline Patient ID & minutes & seconds \\
\hline DN01-01a & 14 & 8 \\
DN01-02 & 15 & 9 \\
DN01-01b & 12 & 33 \\
DN02-01 & 28 & 15 \\
DN02-02 & 42 & 14 \\
DN02-03 & 42 & \\
DN02-04 & $*$ & 56 \\
\hline
\end{tabular}

*not used due to technical failure after initial 2 minutes

\subsubsection{Data Collection Process}

Allowing the nurses time to collect data at a pace that suited their workload was an important feature of the method. Once data collection began, participants were reminded that they could stop or wipe the recording at any stage. 
It was reassuring and encouraging to discover how willingly patients participated. This meant that there would be no shortage of material if some of it was lost due to equipment failure or if someone wanted to withdraw from the study. This in turn eased the pressure on the nurses.

Coordinating nurses, researcher, patient consent and recording equipment required a delicate mixture of patience and timely determination. In the week prior to data collection I explained to the nurse participants that I would have the recorder available if they had suitable patients. This allowed the nurses a week to plan for and obtain patient consent prior to data collection. On data collection days the nurse participants checked the recording equipment with me before making their visits and I labelled and checked the recording afterwards. The two nurse participants adopted different approaches. One placed the recorder on a nearby table. The other placed the recorder in a bag like a passport holder and hung it discreetly under her jacket. The sound quality for both was equally good.

\subsubsection{Equipment:}

The recording equipment was borrowed from Victoria University of Wellington's Linguistics Department.

A portable Sony mini-disc recorder (MZ-R50) was used with a lapel microphone. The microphone was sensitive enough to pick up both speakers clearly even when they moved from room to room or (as happened in one case) into the garden. The batteries and discs were sufficient for over an hour's recording, so that this was not a constraint on the conversations.

It was necessary for the nurses to spend time becoming familiar and comfortable with the recorder. Spare battery and discs were on hand and the recorder was recharged each evening prior to use.

In order to assist the nurse participants, I first learnt how to use it and recorded one domiciliary visit and one office conversation as a pilot. These conversations were not included in the data analysis. 


\subsubsection{Storage and transcription}

The minidiscs were labelled immediately after recording and accompanied by a sheet with the date, track numbers and pseudonyms.

Each original disc was copied to another minidisk (master). The originals were then stored securely and the masters used for transcribing and analysing.

Both sets were then stored securely.

Pseudonyms were used in the transcriptions and any identifying features were removed from the transcript.

\subsection{Analysis}

I listened to the recordings many times throughout the analysis process.

Once transcription of the data was completed, the analysis proceeded in stages. I started with brief and broad descriptions of the content of each conversation, for example 'opening greetings' or 'discussing medication'. A pattern emerged from the data revealing that each nurse-patient interaction included four elements namely: negotiating the agenda, eliciting concerns, a physical examination and planning future care. It was these elements I eventually went on to analyse in more depth.

I was initially interested in studying any features of language where the nurse was either giving information to the patient or asking the patient to do something. However there were so few examples of these activities that I abandoned that approach.

The conversations were analysed for quantitative data on the amounts of nurse and patient talk (using word counts). Knowing who talks most in a conversation can give clues to power dynamics among participants.

I analysed the proportions of social talk and clinical talk. Distinguishing between clinical and social talk was not straightforward and many fragments of the conversations were categorised as both. The most obvious example is "How are you?" The blending of social 
and clinical talk was noted as a strong feature in the data and will be discussed further in the analysis chapter.

As the analysis progressed many interesting features emerged which will be discussed in Chapters 5 and 6.

A detailed analysis of small fragments of "crucial excerpts” followed to bring out evidence of effective communication and nursing expertise.

\subsection{Reflection on the Process / Discussion}

There was no difficulty recruiting patients to the study. They were keen to participate and several took the opportunity to make comments about aspects of language use which were important to them. The nurses also volunteered willingly.

In retrospect it would have been useful for me to allow more time with the nurse participants before and after each recording for several reasons:

- to discuss any immediate impressions or concerns in relation to the process,

- $\quad$ to emphasise how much I valued the data and

- $\quad$ to express appreciation for the extra effort required of them.

It was obvious that, although the nurses had participated willingly, it did put extra stress on their busy working days.

A couple of conversations were lost. To avoid fiddling with the equipment in front of the patient, which may have created an artificial strain at the outset, one nurse set the recorder going before getting out of the car. This created its own difficulties. The first two conversations were lost completely when the nurse inadvertently stopped the recorder by squeezing it into her pocket. This meant that when she returned to the office we anxiously listened to 2 of her recordings to check that they were safely captured. After this she did one more recording, which may have been influenced by a heightened awareness of her language and style of interaction. 
Despite careful preparation to avoid it three people were unintentionally recorded. All were relatives of the patients. Two were spouses and one was a daughter. In each case the person was told that the recorder was switched on and they were then able to continue to participate or withdraw. Verbal consent for their participation was gained at that time.

\subsection{Summary and Conclusion}

This chapter has described how the study of effective communication in a district nursing setting was planned, how the data was gathered and how it was analysed. Using the principles of ethnography an exploratory approach was taken, underpinned by a desire to identify and build on positive aspects of nursing practice.

Nurse specialists acting as key informants recorded their conversations with patients as they occurred in the course of everyday work.

Analysis and interpretation of these conversations relies on in-depth knowledge of the context in which these interactions occur and the values and beliefs which guide nursing practice in this setting.

The following chapters describe the findings. 


\section{Chapter 4}

\section{Analysis of recorded conversations:}

\section{Setting the scene}

\subsection{Introduction}

In this and the following two chapters I use my experience as a district nurse to identify excerpts from the recorded conversations which illustrate how expert nurses go about their work. I then go on to examine the discourse for clues to account for why they are so effective in communicating with their patients.

A combination of discourse analysis and ethnographic analysis was used. These methods of analysis have been discussed in chapter 3 .

Analysis of the data yielded information regarding the content of the conversations and the repertoire of communicative strategies used by the nurses. It also shed light on ways in which nurses build and maintain a professional partnership with patients.

My interpretation of what was meant by what was said in the conversations is based on a combination of my knowledge and experience of the world of district nursing and analysis of linguistic clues in the data in the light of this knowledge. 
I acknowledge that there could be different interpretations. Certainly this study and its interpretation is bound by the context of time and place. To substantiate my interpretations I have provided excerpts from the transcriptions.

This chapter briefly describes the explicit and implicit purposes of the conversations and gives an overview with some comment on the amounts of talk by each participant.

The concept of relational practice is introduced and explored in some detail using examples from the data transcriptions.

\subsection{Purpose of conversations: explicit and implicit}

Nurses making domiciliary visits have an explicit purpose: to attend to the health and well being of the patients. Their conversations, therefore, also have the explicit or "transactional" purpose of attending to any immediate health issues. Health issues include not only physical and emotional needs but also other aspects of health care for example teaching and guiding patients towards managing their changing health circumstances. Sometimes this means managing a lifelong illness and sometimes it means coming to terms with the certainty of a poor outlook.

Typically, the conversations also have one or more implicit purposes. One implicit purpose of the interactions from the nurses' point of view is the "social" function of maintaining and building on an existing therapeutic relationship, sharing the patient's burden of illness, and strengthening the patient's position either through affirmation of the patient's own actions or through facilitating access to skill and information. Another implicit task is to act as mediator or translator between the medical world and the patient's world.

In addition, the nurses have a commitment to working in partnership with patients as expressed in the Model of Community Health Nursing Practice (Andrews, Connor, \& Macdonald 1998). Such a partnership deliberately seeks to enhance collaboration and reduce any power differences between the nurse and patient.

I looked for all these features when analysing the conversations. 


\subsection{Descriptive findings on amounts of talk}

Before making a detailed analysis of the nurse-patient conversations it is interesting to get an overall impression of some general features in the data. One way to do this is to look at the amount of talk; who talks most and how much of the talk is 'professional' or 'on-topic' as opposed to 'social' or 'off-topic'. I will discuss later how the distinction between professional and social talk is not always easy to make.

The question of who talks most in a conversation has been of interest to linguists for many reasons, for example in relation to the gender and power of each participant.

Discovering who talks most has obvious limitations as a crude evaluative approach when what we are searching for is a measure of the effectiveness of the nurses' conversations. However it is a useful starting point for closer analysis. The vast amount of linguistic research already done on the power/gender dynamic contributes to an understanding of what we might expect in a nursing context, although these topics are not pursued in depth in this thesis.

\subsubsection{Gender and power in language}

Studies of the amount of talk provide a clue to how power is perceived by participants in a conversation. Thus most linguistic studies indicate that men talk more than women (despite the stereotype which holds the opposite to be true). Of the 63 studies reviewed by James and Drakich (1993), 56 of them deal with mixed sex interactions. Of these 56 studies, 24 find that men were found to talk more than women overall and a further 10 find that men talk more than women in some circumstances but no difference was found in other circumstances. Similarly, reviews consistently report that men interrupt women more than the reverse (James \& Clarke 1992)

This propensity to male dominance in conversation is usually explained in terms of men claiming more status and power than women and therefore holding the floor as their natural right. Men and women are socialised into these roles and verbal strategies, with men using specific mechanisms to discourage women from speaking (James \& Clarke 1992). 
Another aspect of this phenomenon is the widely reported finding that, in their verbal interactions, men tend to be competitive while women are more likely to be co-operative (Tannen, 1990; Ainsworth-Vaughan, 1998). These authors say that in many circumstances the purpose of talking is different for males and females. Males assert power and status in talk and females maintain harmonious relationships through talk.

Why is this relevant when most of the data involves conversations between women? If dominance in a conversation is indeed related to the need to establish or maintain power and status then it may be assumed that proportions of nurse/patient talk will tell us something about the power and status of the individuals. When both nurse and patient are female the power/status difference is likely to be even more evident, uncluttered by gender as an extra 'confounding variable'.

A more detailed discussion of gender and power can be found in Spender (1980), Ainsworth-Vaughan (1998) and West (1984).

\subsubsection{Patient/nurse conversations}

Because research suggests that power and status are reflected in amount of talk, we might expect that, in a nurse/patient conversation, the nurse will predominate. This is because she is engaged in a professional interaction with a patient and is therefore likely to take a lead role in choosing the topic, eliciting and imparting information, and giving guidance on aspects of health management. Such an expectation would be consistent with studies of other professional interactions for example in classrooms, offices, and medical clinics (West, 1984; Ainsworth-Vaughan, 1998; Hinckley, Craig \& Anderson, 1990.)

But it is very important to take account of social and contextual factors associated with district nursing which significantly alter the expectations of participants and consequently have an impact on the nature of the interactions. The nurse is in someone else's home - in their 'castle', their territory. And she is a guest there, not present by right. On the other hand the fact that the nurse has had to make the visit to the home, instead of the patient attending a clinic or hospital, reinforces that the patient is vulnerable. So there is reason for both parties to be tentative, considerate and polite. 
In their analysis, James and Drakich (1993) refer to social factors as status characteristics and they include in this category: race, sex, educational attainment, and organisational office or job title. Contextual factors might include the setting, how well the participants know each other, who else is present, the nature of the topic and most importantly any preconceptions participants may have.

In a district nursing context the setting, in the patient's home, is obviously important. Preconceptions can also be relevant; they might arise from experiences which have occurred long before and may even include the illness experiences of friends and family decades or generations earlier. Not only must the past be taken into account but also the future. The interaction will be affected by the participants' beliefs and expectations regarding future contact.

\subsubsection{Distribution of talk}

The literature review indicated that various different methods of measuring the amount of talk can be used for example: word count, number of turns, average length of turns and actual time in seconds used by each speaker. There was no obvious advantage of one method over another in analysing nurse-patient conversations. I have used word counts in this study. I chose this method because I thought it would be easier to measure than time and because it would more accurately represent what was happening when overlap or simultaneous speech occurred. 
The percentage of the words in the conversation contributed by each of the participants is shown in Figure 1 and listed in Table 3
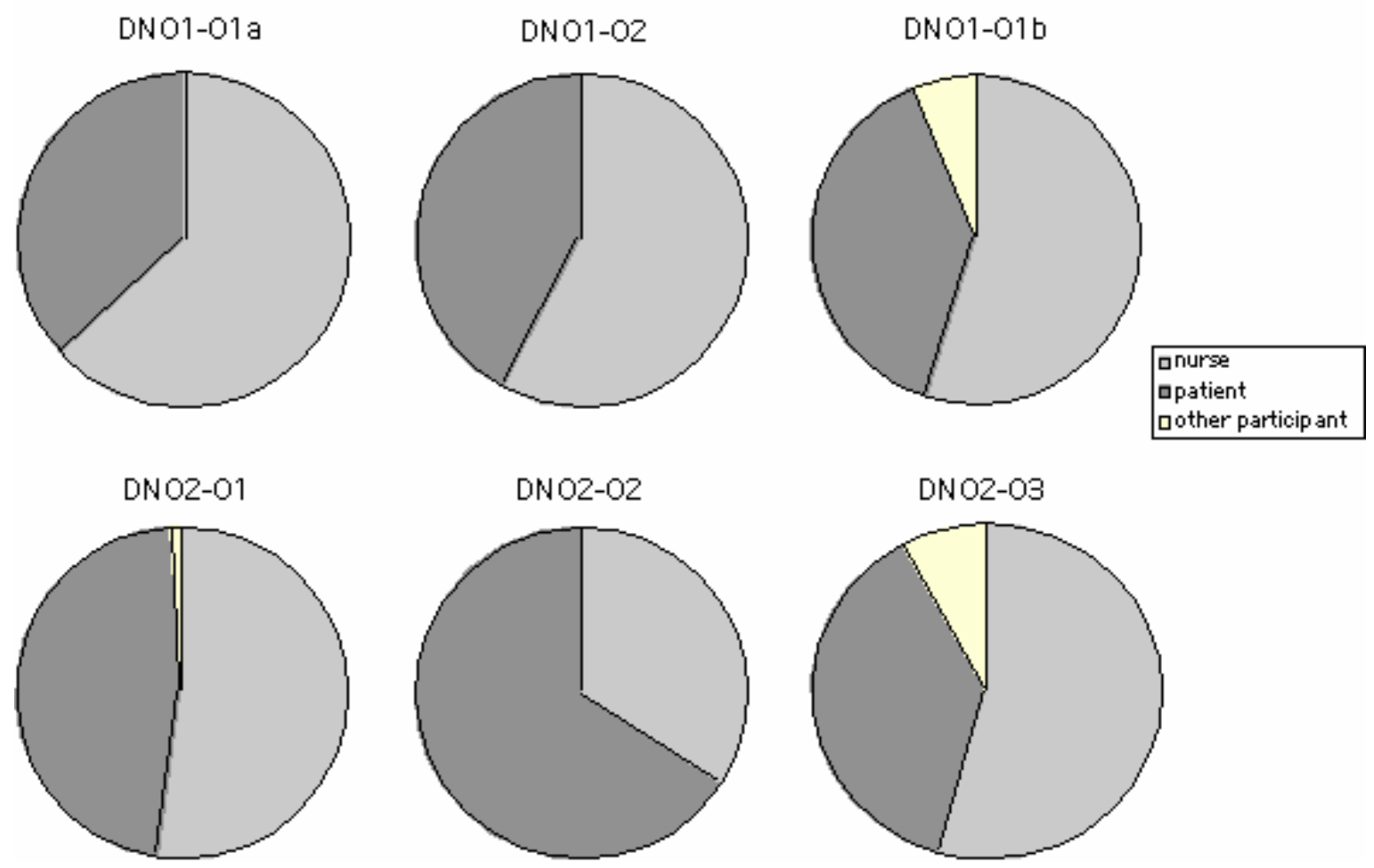

Figure 1: Graphical presentation of the six conversations showing the proportion of the total number of words per participant.

Table 3: Percentage of words contributed by each participant. Actual word counts in brackets.

\begin{tabular}{lllllll}
\hline conversation no. & \multicolumn{2}{l}{ nurse } & \multicolumn{2}{l}{ patient } & \multicolumn{2}{l}{ other participant } \\
\hline DN01-01a & 63 & $(1118)$ & 37 & $(658)$ & - & \\
DN01-02 & 58 & $(932)$ & 42 & $(678)$ & - & \\
DN01-01b & 55 & $(898)$ & 39 & $(642)$ & 6 & $(104)$ \\
DN02-01 & 52 & $(1940)$ & 47 & $(1740)$ & 1 & $(44)$ \\
DN02-02 & 35 & $(1835)$ & 65 & $(3543)$ & - & \\
DN02-03 & 54 & $(2976)$ & 38 & $(2054)$ & 8 & $(434)$ \\
\hline
\end{tabular}


Note five of the conversations have a very similar distribution of words; the exception is the fifth conversation, DN02-02. It is interesting that this is the only male/female interaction, all the others are female/female.

This difference between the female/female and male/female conversations is quite consistent with the assertions noted earlier, that men tend to dominate women in conversations. The fact that in the female/female conversations the amount of talk is in most cases dominated somewhat by the nurses is also consistent with the proposition that the nurses hold the power and reflect this in their conversation with patients even in a district nursing environment. However this may be misleading. The differences between the participants are small and markedly less than in the other professional interactions that have been described (Ainsworth-Vaughan, 1998). The relative evenness in fact suggests the social and contextual factors mentioned above do influence the interaction and the amount of talk although the sample size, six conversations, limits the extent to which this can be generalized.

\subsubsection{On-topic versus off-topic talk}

A second feature of the nurse-patient talk which is useful to analyse is the relative distribution of on-topic versus off-topic talk.

For the purpose of this analysis I have classified on-topic talk as any talk which is immediately and intuitively heard as talk relating to the prime purpose of the visit. Some fragments of conversation could not be classified as one or the other and are called 'unclassifiable' because they were ambiguous or both or on-topic for the speaker but offtopic for the hearer. An example of an unclassifiable fragment of conversation is given:

DN01-03 p.6

Patient I went out yesterday and met some friends for lunch Nurse what did you have for lunch

There are difficulties in defining the difference between on and off topic talk (Coupland, Coupland, \& Robinson, 1992; Coupland, Robinson, \& Coupland, 1994; Coupland, 2000 ) For example the question "How are you?" in this context could be on or off topic depending on whether it was said as a formulaic opening or as a serious inquiry into someone's health. When in doubt about how to classify a piece of dialogue, I have chosen 
with a heavy bias towards on-topic rather than off-topic. Despite this bias, the data shows that a significantly large part of each conversation is taken up with off-topic talk with one exception.

As might be expected in nurse-patient interactions, the data for on/off topic talk shows that on-topic talk predominates (Figure 2). In conversation 6 the patient spoke English as a second language which may explain why there was very little off-topic chat. This suggests there is a problem with small talk in such situations and that patients whose first language is not the same as that of the nurse are likely to be at a considerable disadvantage.

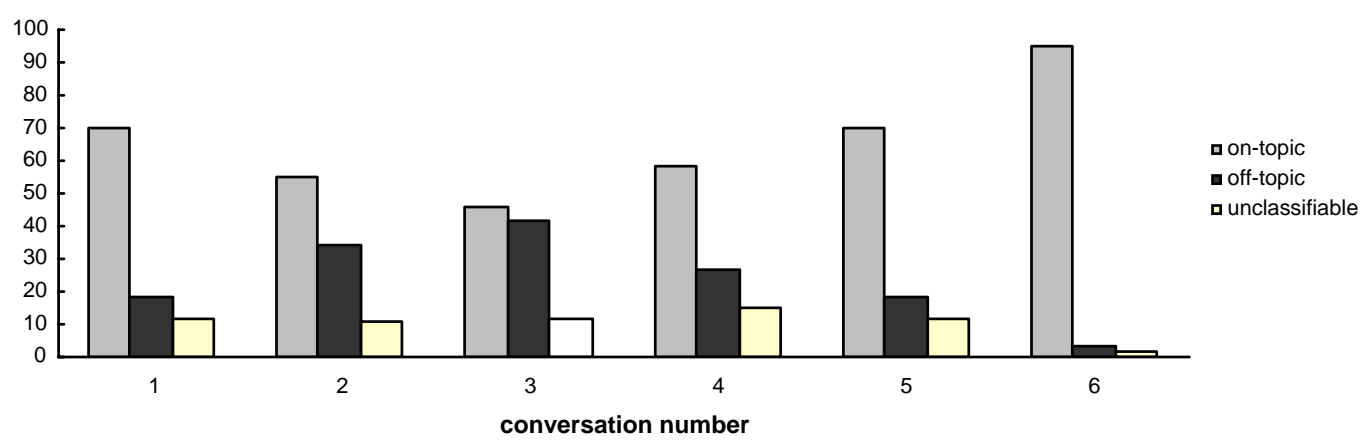

Figure 2: Graphical representation of the six conversations showing the proportion of on/off topic talk

The relevance of professional/business talk and social talk or on/off topic talk will be referred to in Chapter 6.5 and 6.6 when the notion of relational work and small talk is discussed.

To discover more about what actually occurs in the conversations we need to look at the content more closely.

\subsection{What was said: the content of the conversations}

In her study of conversations between Nurse Practitioners and patients, Johnson (1993) states that there are common elements to the structure and content of every consultation that she observed in the nurses’ consulting room. These were:

- $\quad$ establishing the agenda, 
- eliciting information from the patient,

- doing a physical examination and

- planning future care.

From my experience these components closely match the usual way in which New Zealand district nurses work, with the addition of a fifth element which is discussed at the end of the present chapter:

- relational practice.

Relational practice builds and maintains relationships using a variety of skills one of which is language choice.

Using these components as a framework the data is analysed in this study to identify examples of how nurses express themselves to achieve the desired outcome for the conversation.

Chapter five sets out an in-depth analysis of what the nurses and patients talked about.

\subsection{How it was said: the linguistic repertoire of the nurses}

Having analysed the content of the conversations between nurses and patients it is then useful to look at some of the communicative strategies used by the nurses. Analysing these strategies helps explain how the nurses dealt with the topics or content of the conversations. I have identified and drawn out common strategies which were present in all the conversations and will discuss each briefly in turn. These strategies were:

- matching voice tone

- commentary

- humour

- small talk

- strategic use of multifunctional questions

- teachable moments

- relational practice 
Relational practice, mentioned earlier as a feature of the content of every conversation, is included here as a means by which 'content' was discussed. Relational practice has a unique place as being both a tool and a trait of clinical practice.

Chapter six sets out an in-depth analysis of how the nurses talked about the topics discussed in chapter five.

\subsection{Relational practice}

The fifth element in each of the recorded conversations, in addition to the four described by Johnson (1993), I have identified as relational practice. In discussing relational practice in an engineering firm, Fletcher (1999) says it includes all those "off-line, backstage or collaborative” activities that support others and go largely unrecognised and unrewarded.

Relational practice is the work that goes in to build the relationship between carers and the patient. As indicated in the literature review in Chapter 2 this relationship between carers and the patient is crucial to the outcome of care. Care is more likely to be effective when the patient has trust and confidence in that care and when care is well co-ordinated and consistent. We explore the concept of relational practice here so it is available for the analysis described in the next two chapters.

Having trust and confidence in care is not easily achieved and can all too readily be shaken. Often patients are coping with unfamiliar information, with choices and treatment options. They may seek advice not only from medical professionals but also from family, friends and the internet, which may be confusing or contradictory. It often falls to the nurse to help make sense of these issues and contradictions, to build an environment of coherence and trust and to affirm the patient's actions. Building trust may involve relatively straightforward logistical matters such as ensuring the right equipment is available when it is needed or it may involve dealing with complex personal issues.

In a nursing context, relational practice includes sharing the burden of illness and

providing other kinds of emotional support. While relational practice is directed primarily at the nurse-patient relationship, the nurse may also be mediating or translating between 
the patient and other health professionals and between the patient and the family and other carers.

It is easy to overlook the significance of relational practice in a medical world which places value on biological processes rather than a person's response to disease or injury which is the explicit and avowed focus of nursing. Relational practice is crucial to achieving the purpose of district nursing and was evident throughout all the recorded conversations. It is a feature of nursing which is often underplayed or overlooked and it is notable that Johnson (1993) does not mention it in her study. The examples given below show some of the contexts and ways in which relational work is done.

Sometimes the nurse is performing a mediating or translating function between the medical world and the patient's world. This may be to resolve differences between the patient's wishes and medical advice.

Example 4.1 illustrates how the nurse handles this kind of dilemma. The doctor wants the patient to use oxygen 24 hours a day and has suggested he use a stationary bicycle for exercise instead of aqua-jogging so that he could keep having oxygen during exercise. The patient prefers aqua-jogging because it's very relaxing and very pleasant and he dismissively calls a stationery bicycle a 'nine-day wonder'. The excerpt illustrates how the nurse assists the patient to make a decision with all the facts to hand. The nurse's response in line 2 supports both the doctor and the patient and encourages the patient to explore the topic further. ${ }^{1}$

Example 4.1 Context: Discussing exercise when medical advice differs from patient's wishes. The doctor wants the patient to use oxygen 24 hours a day. [DN02-02 Transcription p.28]

\footnotetext{
1 Patient but Doctor Morris is so insistent that I should try and get as close to twenty four hours as I can possibly do

2 Nurse $\quad \mathrm{mm} \mathrm{mm}$ and that's the optimum and and clinically that's that's what's advisable best medical practi practi um practice but at the end of the day er you incor- there's

3 Patient $\mathrm{mm} \mathrm{mm}$
}

\footnotetext{
${ }^{1}$ See Appendix 3 for transcription conventions
} 
This blending or translating function is shown again in the next example where they are discussing how best to take frusemide medication. The patient has been making an educated guess at adjusting dosages. The task is complicated for both nurse and patient because there are already three doctors involved, each with slightly differing views.
Example 4.2 Context: Discussing options when medical advice differs between professionals
[DN02-02 Transcription p.16]

1 Nurse It's kind of not clear though is it .........I suppose from my perspective just by taking three quarters of a frusemide once you you're not kind of achieving anything it's it's not it doesn't seem to me to be the most appropriate way to use it.

2 Patient it certainly didn't work er

3 Nurse and I would wonder yeah and I would whether you'd be better off to say take half a tablet for a week or take a whole tablet for five days or something like that to get the effect and then stop

$\cdots$

4 Nurse should we ask one of them I mean would you like to I-I'm happy to ring Doctor Sutherland or Doctor Morris talk to them or would you rather do it

This illustrates how the nurse positions herself. She shows the patient that she recognises she is one of many voices expressing an opinion here. Interestingly the patient eventually chooses to take frusemide in a certain way and to inform the doctor of what he is doing. The patient uses humour to mitigate this departure from conventional practice. The nurse acknowledges this with a laugh and brings the conversation back to the detail of what he actually intends to do.

\section{Example 4.2 Continued ...}

$\begin{array}{rll}5 & \text { Patient } & \text {.....talk about being up with the latest I could send him an e-mail } \\ 6 & \text { Nurse } & \text { course you could course you could } \\ 7 & \text { Patient } & \text { and say Doctor Sutherland sorry to trouble you but } \\ 8 & \text { Nurse } & \text { yes } \\ 9 & \text { Patient } & \text { this is what I'm doing } \\ 10 & \text { Nurse } & \text { yes ok } \\ 11 & \text { Patient } & \text { if you think it's desperately wrong send an ambulance and er send a district nurse or } \\ & & \text { whatever } \\ 12 & \text { Nurse } & \text { [laughs] e-mail back urgently [laughs] } \\ 13 & \text { Patient } & \text { yes e-mail back urgently but that's fair enough I can keep him informed that way } \\ 14 & \text { Nurse } & \text { mm } \\ 15 & \text { Patient } & \text { um } \\ 16 & \text { Nurse } & \text { so what do you think you'll do start } \\ 17 & \text { Patient } & \text { well what do you think I'll I'll say start tonight }\end{array}$


Here the nurse is listening attentively to the patient, matching the tone and pace of his conversation. She senses, correctly, that he is going to make his own decision about medication and she wants to know what that will be. She also wants to include the patient's GP in the process and so the nurse successfully guides the patient towards that.

Sometimes the nurse may act to avoid a potential conflict.

Example 4.3 Context: The patient is anxious about an unusual noise which has started in his oxygen machine and the machine is due for servicing. He has already phoned the technical department once to ask about it. [DN02-02 Transcription p.22]

1 Patient and from time to time it gives a little sort of brrr psss sound that shouldn't be there and then I move it a little bit and it's okay again so I don't know what that means but

2 Nurse mmm I'll just mention it gently to her again tomorrow

Patient well look please don't er

4 Nurse no I won't rock the boat

5 Patient I wasn't complaining or anything it was more along the lines of Nurse no no no

7 Patient gosh fancy that kind of thing

8 Nurse yeah yep no no she won't have considered it as complaining she um it's always good to be sure rather than sorry

Here the nurse is attending to the patient's anxieties while maintaining good relationships with the technical department. The nurse is sensitive to the patient's desire to avoid conflict with the technical department on whom he is heavily dependant.

While focussed on health issues, relational work can nevertheless involve family relationships as in the following example (given later as an example of small talk but equally valuable in this context).

Example 4.4 Context: Nurse and patient are well into their conversation when the patient's husband appears. This fragment of conversation happens as an aside.

[DN02-01 Transcription p.11]

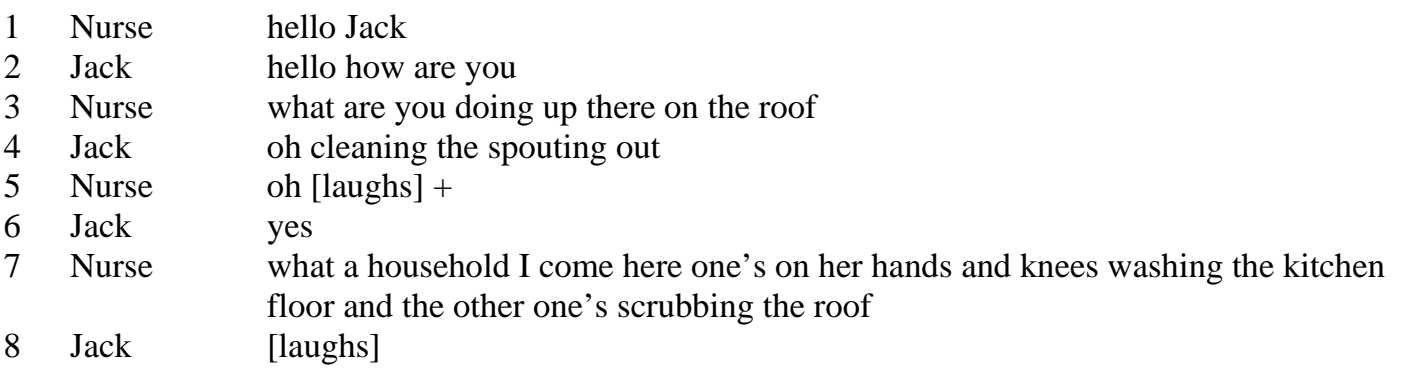


9 Nurse do you think you're only twenty one or something [laughs]

To the hearer this is a casual inconsequential aside to the main conversation: I have used it later as an example of small talk. Notice how the nurse initiates the greeting, immediately including the husband in the conversation leaving him in no doubt about whether it is appropriate for him to join in and she uses his name. Lines 1 and 2 are conventional greetings. In line 3 the nurse deflects attention away from herself and asks him what he is doing. By asking the question, the nurse is showing an interest in his activity and making sure he knows he is included. In line 7 she is giving a veiled compliment to them both on their vigour. She reinforces the compliment in line 9 by asking Jack if he thinks he's twenty one or something.

This brief episode is evidence of the relational work nurses do. A holistic approach to health, which underlies nursing practice, naturally includes family members as part of the patient's world.

In Example 4.5 which follows, the nurse is gathering information and beginning to plan future care but the main value lies in the relational work she is doing. Here the patient is broaching the topic of his deteriorating condition and looking to the nurse for emotional support.

Example 4.5 Context: keeping active in the face of a deteriorating chronic condition.

[DN02-02 Transcription p.24]
1 Patient
I mean I should be more active than I have been but it's sort of all become so much you know $1 / /$ and I $\$ that's (why) I was a bit down last week 2 / or so $\ \backslash$ because you think oh dear oh dear (we're now) sort of doing the last bit down the slide and then it's going to be a pretty steep one oh dammit
2 Nurse $1 / \mathrm{mm} \backslash 1$
2 / $\mathrm{mm} \backslash 1$
$3 \quad$ it's a whole journey of letting goes isn't it
4 Patient yeah yeah well pretty well but er there you go
5 Nurse $\quad$ well let me give you a wee bit of a hopeful one I don't know if I've mentioned the
6 Patient yes you have and Doctor Morris also has said why don't you come to that

The nurse is listening attentively to the patient's account and summarising what has been said. The nurse shows she is listening by providing feedback to the patient in the form of “mm” "mm”. She indicates an appreciation of the deeper implications of what he has said 
by summarising in Line 3. In this way she has shared the burden of his illness. The nurse then tentatively offers a practical means of seeing the future in a hopeful way. The tentativeness of her suggestion in line 5 allows him to decline it without seeming ungrateful or impolite. The nurse makes the suggestion in this manner when she expects a negative response and in this way she is preserving the relationship.

These examples of relational practice give a glimpse of how useful the work may be. Its therapeutic value needs to be made explicit if it is not to appear as inconsequential chat.

Because relational work such as sharing the burden of illness and emotional support is quite demanding on the nurses, it requires personal maturity to undertake it freely. Such a degree of 'giving' is a characteristic of an expert nurse.

\subsection{Summary}

This chapter serves as an introduction to the more detailed analysis which follows in the next two chapters and includes a brief explanation of the explicit and implicit purposes of conversations in the data.

An overview of the amounts of talk reveals that, unlike other interactions between professional and clients, the distribution of talk between participants is comparatively even. This suggests that two factors are having a significant impact on the interaction: the context (the conversation is in the patient's own home) and the nurses' commitment to working with patients in partnership. Also, consistent with other linguistic studies, males predominate in conversations between male and female.

The concept of relational practice, which builds and supports the purpose of nursing, is introduced and developed using excerpts from the transcribed conversations. 


\section{Chapter 5}

\section{Analysis of recorded conversations:}

\section{Structure and Content}

\subsection{Introduction}

In this chapter I look at what was talked about: the content of the conversations. I have already noted that in her study Johnson (1993) states that there are common elements to the structure and content of every consultation that she observed in the nurses' consulting room. These were:

- establishing the agenda,

- eliciting information from the patient,

- doing a physical examination and

- planning future care.

A fifth element, relational practice, has been discussed in the previous chapter.

Each of these elements observed by Johnson was also evident in the data obtained in this present study and received a slightly different emphasis in the different conversations. The major differences related to whether the patient's condition was acute and rapidly 
changing or chronic and relatively stable. All the conversations opened with negotiation of the agenda and closed with a discussion arranging the next visit.

\subsection{Establishing the agenda}

A domiciliary visit by district nurses is most productive if the nurse and the patient are working towards the same goals. To ensure this happens they need to discuss at the outset what these goals are. Usually the nurse will be visiting the patient for a specific reason for example to assess post-operative recovery or to help a patient come to terms with a new diagnosis. There is a purpose to the visit and the goals for the nurse are fairly obvious. However the patient may be anticipating the nurse's visit as an opportunity to resolve quite different issues that have arisen for them. These may be practical issues such as supplies of consumables or worries about the progress of their illness. Experienced nurses, therefore, realise that one of the first phases of the meeting will be to negotiate the agenda.

At the outset of each interaction in this study, nurse participants made a point of facilitating the negotiation of the agenda. The following examples from the transcripts show how this can be done in a simple, informal, yet very effective manner.

The first example typifies the process where, after some initial greeting, the nurse turns her attention to the business part of the visit. She is open to hear any concerns the patient may have. Even if this does not appear to be specifically setting an agenda, the nurse is allowing the patient to take the lead in setting the first topic for discussion. In fact the nurse avoids embarking on any topic until the patient has done so.

\begin{tabular}{|c|c|c|}
\hline \multicolumn{2}{|c|}{ Example 5.1} & $\begin{array}{l}\text { Context: Two minutes into the domiciliary visit } \\
\text { [DN02-01 transcription p.6] }\end{array}$ \\
\hline 1 & Nurse & anyway how’ve you been \\
\hline 2 & Patient & well as I said before up and down although the last day I've been up \\
\hline 3 & Nurse & yeah? \\
\hline 4 & Patient & I've been feeling really good \\
\hline 5 & Nurse & have you? yeah \\
\hline 6 & Patient & I've increased my combivent to five times a day \\
\hline 7 & Nurse & nebuliser or? \\
\hline 8 & Patient & nebuliser \\
\hline 9 & Nurse & nebuliser right \\
\hline 10 & Patient & and um I've also gone onto the morphine um more four times a day.... \\
\hline
\end{tabular}


Using the word 'anyway' serves a particular function. In line 1 the nurse is signalling the end of small talk and the beginning of her nursing assessment. In this way she propels the conversation towards the business of the visit while leaving the actual specific topic open for the patient to establish. In Line 3 and Line 5 the nurse keeps prompting until the patient responds with a comment about her medication.

In Example 5.2 we see how the nurse moves from her opening greetings into tentatively setting the agenda.

Example 5.2 Context: Opening to domiciliary visit. The nurse and patient know each other quite well and have established that they prefer to attend to the business of the visit without delay.

[DN01-02 Transcription p.4]

$\begin{array}{rll}1 & \text { Nurse } & \text { hi is that your nice red car out there } \\ 2 & \text { Patient } & \text { yes } \\ 3 & \text { Nurse } & \text { oh } \\ 4 & \text { Patient } & \text { [laughs] } \\ 5 & \text { Nurse } & \text { didn’t you have a little } \\ 6 & \text { Patient } & \text { grey thing? } \\ 7 & \text { Nurse } & \text { //yes } \backslash \\ 8 & \text { patient } & \text { /yes \ that's my new toy } \\ 9 & \text { Nurse } & \text { how wonderful //when did } \backslash \text { you get it } \\ 10 & \text { Patient } & \text { //yeah } \backslash \\ & & \text { only a couple of about a week before I went into hospital } \\ 11 & \text { Nurse } & \text { oh very nice } \\ 12 & \text { Patient } & \text { yes } \\ 13 & \text { Nurse } & \text { nice comfortable seat } \\ 14 & \text { Patient } & \text { oh yes [laughs] } \\ 15 & \text { Nurse } & \text { [quietly] oh good: how are you } \\ 16 & \text { Patient } & \text { oh pretty good pretty good } \\ 17 & \text { Nurse } & \text { now did I tell you I was going to bring some more powder? }\end{array}$

At line 13 the nurse skilfully and subtly indicates that she is turning the conversation towards the business of her visit. The nurse is acknowledging that the patient will need a comfortable seat because of the surgery she has had. The patient recognises this and laughs. At the same time the patient is given the choice of continuing to talk about the car or switching to the business of the visit. In line 13 and again in line 15 the nurse is giving the patient opportunities to set the topic and pace of the conversation. This example shows how quickly the nurse moves from greetings to business talk. When nurses have a busy workload, the ability to work quickly while still attending to the norms of social manners and appearing unhurried is a distinct advantage. 
Example 5.3 Context: Opening of visit.

[DN01-03 transcription p.4]

$\begin{array}{lll}1 & \text { Patient } & \text { come in } \\ 2 & \text { Nurse } & \text { [laughs]hello how are you } \\ 3 & \text { Patient } & \text { [laughs]good thanks } \\ 4 & \text { Nurse } & \text { I've got the recorder on again } \\ 5 & \text { Patient } & \text { okay //it's not a/ problem } \\ 6 & \text { Nurse } & \text { /is that okay?// } \\ 7 & & \text { right how are you } \\ 8 & \text { Patient } & \text { good }\end{array}$

Five lines later the nurse asks for the third time, "How are you?" This time the question is preceded by a significant pause. A significant pause is a linguistic clue that the speaker is marking a boundary or signalling a transition from small talk to the business in hand or purpose of the visit. As Coupland, Coupland and Robinson (1992) point out in their article entitled "How are you?" Negotiating phatic communion patients may wish to enter into a disclosure about their health in a slowly progressive tentative manner.

Asking a very general question such as “How are you?” gives the hearer an opportunity to raise any concerns and thereby set the agenda for the visit. Knowing the potential for the patient to have many different issues to discuss and the reticence some patients have towards self-disclosure the nurse typically makes several openings for this to occur. These are just examples of a general pattern.

\subsection{Eliciting information}

In all six conversations information was elicited throughout the interaction and not as a separate discrete phase. Many strategies were used by the nurses to elicit information. Example 5.4 illustrates simple direct questioning.

Example 5.4 Context: Discussing use of medication where the patient is varying the dose.

[DN02-01 Transcription p.7]

1 Nurse so when you talk about increasing it more .... how much are you talking about going

2 Patient well I sort of was just taking it at night time 


$\begin{array}{lll}3 & \text { Nurse } & \text { yeah } \\ 4 & \text { Patient } & \text { but now I take it during the day as well um } \\ 5 & \text { Nurse } & \text { and it's always two point five? }\end{array}$

The transcripts show that generally the nurses encouraged patients to elaborate on their responses to questions. This led to a kind of narrative which furnished the nurses with a useful picture of the patient experience and also the patient's priorities and values as in Example 5.5 (and Example 5.9 further on in this section)

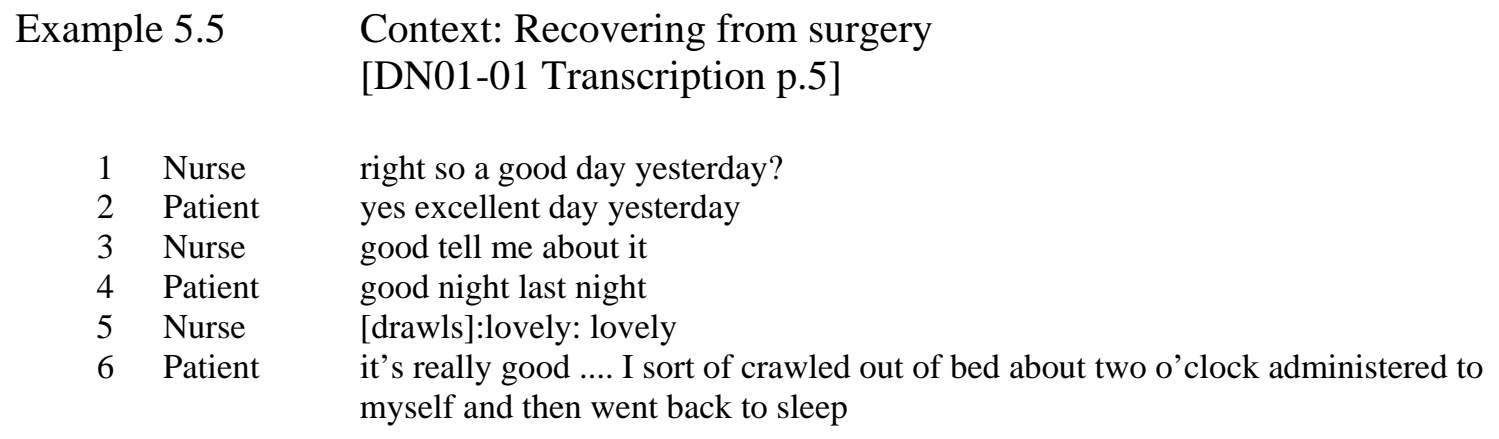

With the response given by the patient in line 2 "yes excellent day yesterday" the nurse could easily have moved on to the next question but instead she asks for elaboration using a classical open-ended question, "good tell me about it". This is important because, as the reply indicates, we all have different interpretations of an 'excellent' day. An experienced nurse will not make assumptions about what is meant.

Example 5.6 Context: The patient's main problem is severe respiratory disease but here the nurse is enquiring about the impact of recent hip surgery on the breathing. [DN02-01 Transcription p.18]

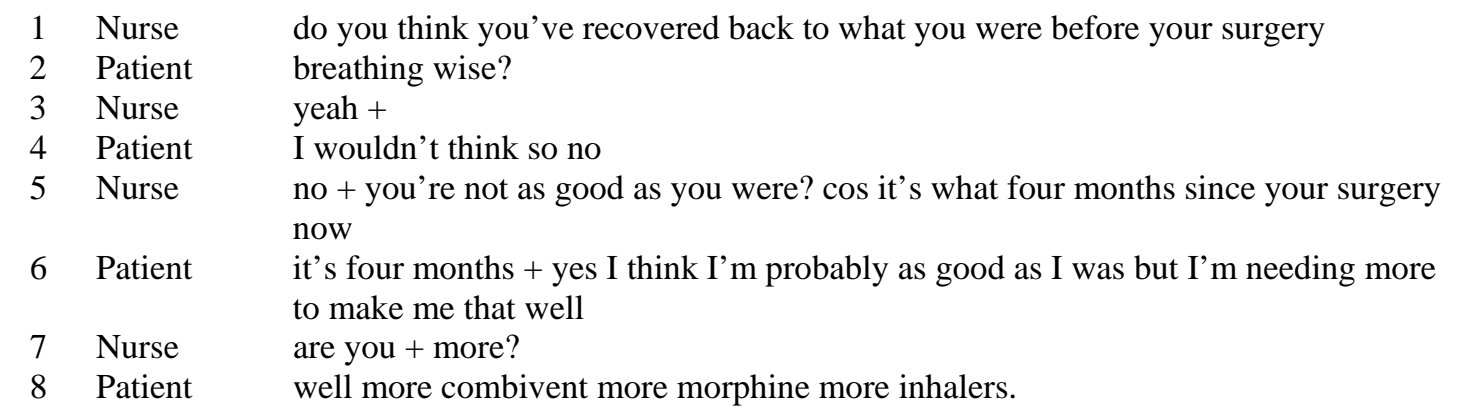

In line 1 the nurse is using a general question to seek information but she is also implicitly acknowledging the expertise of the patient and the validity of the patient's viewpoint. The 
question invites comment on physical and emotional aspects of the surgery. It exemplifies the values and beliefs which underlie this nurse's practice i.e. that nursing is a partnership in which the patient's viewpoint is as valid and relevant as that of the nurse. In turn this stance enhances and deepens the connection between these two participants. The same question from a nurse not known to this patient may just cause irritation. The value of this fragment of the conversation lies in part in the existing relationship they have. The example illustrates the multifunctional nature of the nurse's question in line 1 . She is eliciting information at the same time as acknowledging the patient's expertise. This example also illustrates how much insight patients have into their own condition and how expertly they cope with it. An expert nurse knows how to elicit and build on the patient's own insight.

\subsection{Physical Examination}

In some cases the physical examination occurred as a discrete part of the interaction and in others it was interspersed with off-topic chat. In all cases the nurse gave a 'commentary' on what she was doing and what she was noticing and recording. This kept the patient included, informed and reassured. It was frequently a time when nurses took an opportunity to share information about specific health issues as questions arose from the patient.

\section{Example 5.7}

\section{[DN01-01 Transcription p.9 ]}

1 Nurse okay I would like to take your flange off today and have a look at your skin underneath that

\section{Patient yeah cos it's very itchy at the moment}

..............see the rash there

4 Nurse oh that's simply because the skin's been exposed I'll just be [drawls]: very : gentle

$5 \quad$ that little bit of um rash is what we call excoriation and it's simply where the skin's been exposed to the motion

Patient yeah

7 Nurse and that will settle down // by $\backslash$ the time we take this off on er Monday

8 Patient /yeah\\ 
In line 1 the nurse is clearly saying what she would like to do but expressing it in such a way that the patient has an opportunity to negotiate. The 'yeah' in line 2 represents agreement and permission from the patient and is quickly followed by her own reason for wanting this examination done. This small exchange reveals the partnership in the relationship. They go on to discuss skin care and the nurse gives information on how to manage certain skin problems.

The next example comes from an interaction where the patient showed a detached curiosity about this aspect of the visit. Of much greater concern to her than this physical examination was attentiveness to her subjective account of current good physical health, in spite of the physical restrictions it entailed and the emotional impact it was having from time to time.

Example 5.8 Context: Domiciliary visit to a patient with chronic respiratory disease. The patient has been saying how well she feels. The nurse is taking oxygen level readings from a pulse oximeter [DN02-01 Transcription p.21]

$\begin{array}{rll}1 & \text { Nurse } & \text { okay let's see what your oxygen’s doing you're still on one litre? two litres } \\ 2 & \text { Patient } & \text { two litres } \\ 3 & \text { Nurse } & \text { two litres that's right }++ \text { the machine going okay and all? } \\ 4 & \text { Patient } & \text { mm good } \\ & \ldots \ldots \ldots \ldots . . . & \\ 5 & & \text { ninety seven } \\ 6 & \text { Nurse } & \text { my word } \\ 7 & \text { Patient } & \text { ninety six } \\ 8 & \text { Nurse } & \text { you ARE having a good day } \\ 9 & \text { Patient } & \text { mm } \\ 10 & \text { Nurse } & \text { even the machine tells us so } \\ 11 & \text { Patient } & \text { mm } \\ 12 & \text { Nurse } & \text { that's good for you isn’t it } \\ 13 & \text { Patient } & \text { it is it’s very good }\end{array}$

Notice in lines 5 and 7 that it is the patient who is reading off the measurements. In line 10 the nurse acknowledges that the machine readings are an adjunct to the patient's subjective account of her health rather than the machine being the prime arbiter of well-being. In this way the nurse strengthens the patient's position in the partnership between them. 


\subsection{Developing a plan of care}

Developing or updating a plan of care is an integral part of every district nursing visit. Planning care is usually a collaborative process and often involves not only the patient and nurse but also other health professionals and the patient's friends and family.

Experienced nurses anticipate the likely course of events and develop a plan which takes into account not only the immediate health concerns but also those which may arise in future. In discussing the plan, the nurse needs to find a balance between preparing a patient for what is ahead and protecting the patient from undue anxiety. In Example 5.9 the nurse indicates that she is aware that episodes of breathlessness are likely to get worse.

Example 5.9 Context: Discussing inhalers and how to manage breathlessness in the middle of the night [DN02-01 Transcription p.20]

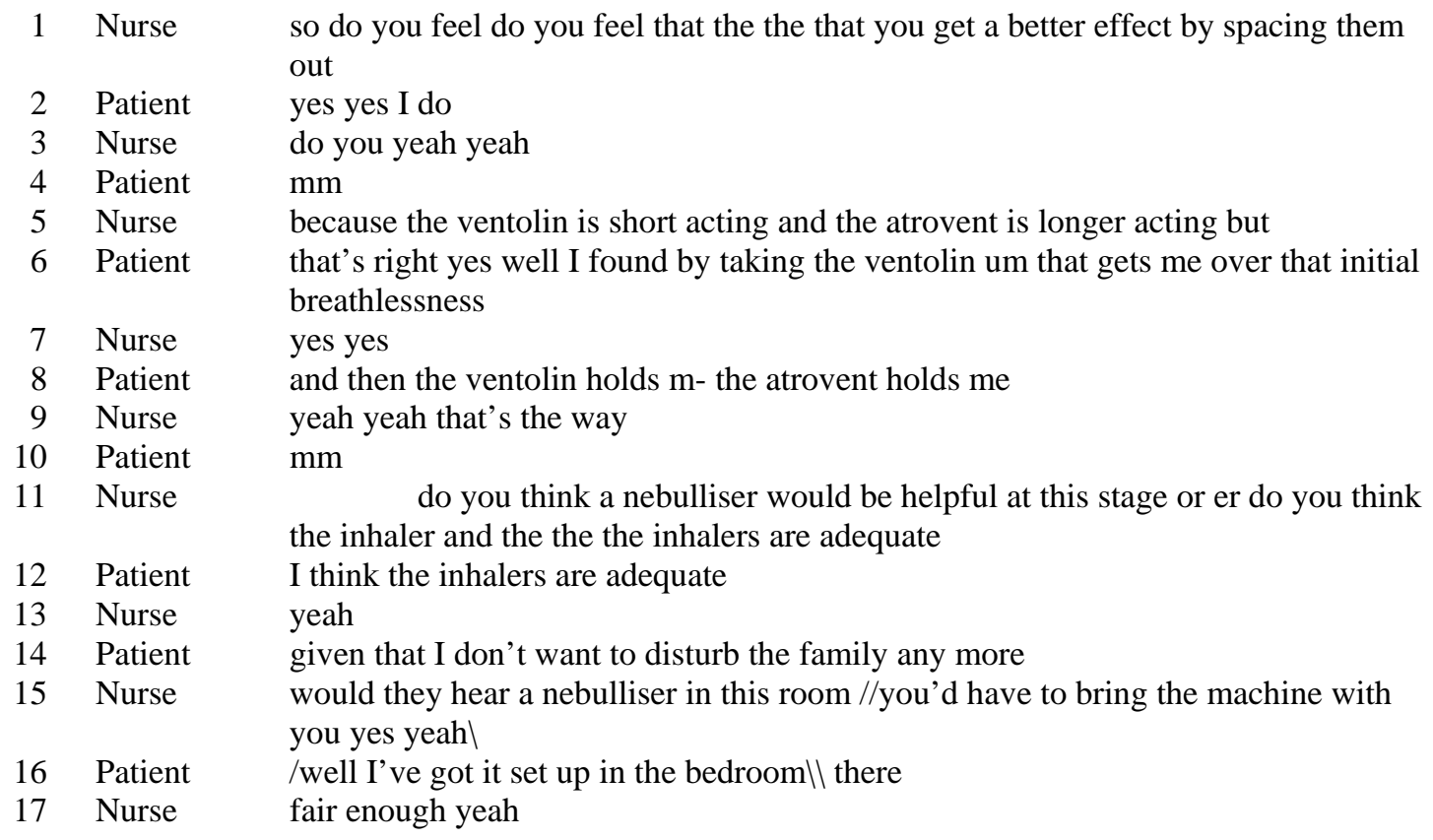

In this example the nurse is guiding the patient towards ways of managing troublesome symptoms. Developing a plan of care includes anticipating future events and the nurse is aware that these symptoms of breathlessness are likely to worsen with time. In this instance the patient has a plan which is working and she does not want to change anything. The nurse uses the word 'adequate' in line 11 in association with the inhalers which indicates to me that the nebulliser which she is suggesting would ease the symptoms more 
effectively. The patient chooses to use the inhalers rather than something possibly more effective because she doesn't want to disturb the family any more. The nurse replies 'fair enough yeah' in Line 17 which is an interesting construction. This suggests that the nurse concedes that the patient has a good reason not to take up her suggestion. It illustrates collaborative practice and the power sharing in their partnership.

In Example 5.10 the nurse is directing her comments to the patient and the patient's spouse recognising the value of including families in planning and understanding patient care.

Example 5.10 Context: Towards the end of a domiciliary visit to a patient with chronic respiratory disease. The patient's spouse is clarifying his understanding of how to regulate the amount of oxygen delivered by the machine [DN02-03 Transcription p.43]

\begin{tabular}{|c|c|c|}
\hline 1 & Spouse & and you can't turn that up can you? \\
\hline 2 & Nurse & $\begin{array}{l}\text { yeah um you CAN turn it up but I } 1 / / \text { I } \backslash \text { I’m advising Maisie to keep on two } \\
\text { because sometimes if you make the oxygen too strong it doesn't help it makes you } \\
\text { feel all dizzy and drowsy and } 2 \text { // sleepy } \backslash\end{array}$ \\
\hline 3 & Patient & $1 /$ no more noll \\
\hline 4 & & 2 /yeah \\
yeah \\
\hline 5 & Nurse & and gives you a headaches so two's enough that's enough for Maisie to go up to two \\
\hline & Patient & oh thanks \\
\hline 7 & Nurse & $\begin{array}{l}\text { okay so I'll write down here that um that I've advised you to use it most of the time } \\
\text { while you're at home }\end{array}$ \\
\hline$\varepsilon$ & Patient & okay dear \\
\hline
\end{tabular}

In line 7 the nurse is writing the patient care plan and reading aloud as she does so. This activity underlines what she has already discussed, emphasises the importance of this advice and formalises the plan for future care. It is almost like a contractual arrangement.

The plan of care always included an implicit or explicit time for review, usually at the next visit. All the interactions in this study concluded with some kind of discussion about the timing of the next nursing visit. The time of the next visit varied from the next day to three months away. The plan, therefore, spanned this time frame. 


\subsection{Summary and Discussion}

The preceding examples have shown that all four elements which make up the content of a consultation described by Johnson (1993): setting the agenda, eliciting information, conducting the physical examination and developing a plan of care are found in the domiciliary visit of a District Nurse. A fifth element, relational practice, has been discussed earlier.

It is interesting to note the range and versatility of these nurses in adapting conversational styles to suit the patient and the predicament. The nurses manage the entire home visit smoothly moving from greetings and social chat to the explicit purpose of the visit, alert to the possibility that there may be other issues, potential conflicts and other people to attend to along the way.

The next chapter exposes and analyses how this is done. 


\section{Chapter 6}

\section{Analysis of recorded conversations:}

\section{Linguistic repertoire of the}

\section{nurses}

\subsection{Introduction}

Having analysed the content of the conversations between nurses and patients in chapter five, this chapter focuses on some of the communicative strategies used by the nurses. Analysing these strategies helps explain how the nurses dealt with the content of the conversations. I have identified and drawn out common strategies which were present in all the conversations and will discuss each briefly in turn with examples from the transcripts. 


\subsection{Matching voices}

Listening to the recorded conversations I noted that the nurses matched their voice tone and rate with that of the patients with whom they were conversing. This in itself is a means by which the nurse aligns herself with the patient. It is a marker of a cooperative, collaborative, supportive approach. It signifies attentiveness and mutual respect in the interaction. Matching voice tone in this way is a linguistic feature of communication accommodation theory (Holmes, 2001).

\subsection{Commentary}

At times throughout the conversations the nurses gave a brief commentary on what they were observing or doing or writing. For example during the physical examination they would do this to prepare and involve the patient.

Example 6.1 Context: Changing a colostomy bag [DN01-02 Transcription p.9]

1 Nurse now I'm just going to give this a wee wipe //because $\$ I think if we don't that we'll

have a

2 Patient /yep $\backslash$ mess

3 mess

4 Nurse a mess on the toe

5 Patient yeah

6 Nurse yeah that's miles better

7 Patient yeah

As well as preparing and involving the patient the commentary served other functions. During unpleasant or unfamiliar procedures e.g. changing a colostomy bag, the matter-offact tone of the commentary helped to normalise the process and reduce any sense of stigma or embarrassment the patient may feel. In Lines 4 and 6 the nurse is echoing the actual words used by the patient which reinforces the fact that they are undertaking a shared task and strengthens the notion of a partnership.

In the next example the nurse summarises what the patient has been telling her. By doing this she is able to verify her understanding and at the same time give him an opportunity to review his own position. The nurse is facilitating his decision-making. 
Example 6.2 Context: Discussing the merits of swimming as exercise [DN02-02 Transcription p29.]

\begin{tabular}{|c|c|}
\hline Nurse & $\begin{array}{l}\text { the big thing that you said to me seemed to me to be the relaxing effect it has for } \\
\text { you which walking doesn't have }\end{array}$ \\
\hline Patient & oh absolutely no \\
\hline Nurse & $\begin{array}{l}\text { um so there's there were a lot of things you described there that( it's they're worth) } \\
\text { holding on to }\end{array}$ \\
\hline & Imm well there’s also just a little practical thing.... \\
\hline
\end{tabular}

When associated with writing in the care plan, the commentary restated and emphasised what had been discussed and what was being written.

Example 6.3 Context: Writing results of a physical examination in the nursing notes.

[DN02-01 Transcription p.25]

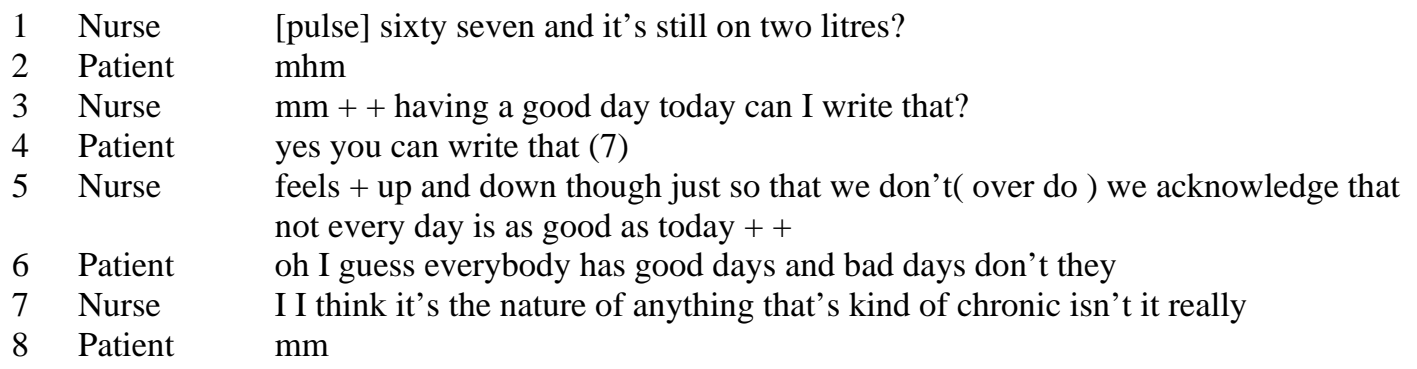

Here the nurse is using a commentary as a means of verifying her assessment of the patient and to provide an opportunity for the patient to elaborate.

\subsection{Humour}

Humour serves many functions. Primarily it builds relationships and reduces tension and embarrassment. In the example that follows the nurse uses humour (by addressing the patient in the third person) to approach a sensitive issue. The sensitivity is around the nurse's role in the house. As a visiting nurse in someone's home it is not always clear as to who is 'in charge'. Is it the 'professional' or is it the host? Until the nurse and patient know each other better these boundaries and ground rules are unclear and the nurse does not want to cause offence either by leaving a messy bathroom or by 'tidying' someone else’s space. 
Example 6.4 Context: The nurse is tidying the bathroom after assisting the patient in changing a colostomy bag. It is the patient who is the "lady of the house". [DN01-01 Transcription p.16]

$\begin{array}{lll}1 & \text { Nurse } & \text { alright now we better leave the place tidy or the lady of the house won't let us back } \\ 2 & \text { Patient } & \text { thank you very much } \\ 3 & \text { Nurse } & \text { [laughs] okay }\end{array}$

It is interesting to note that although the tone of the interactions in the data was generally relaxed and friendly, overall there was very little use of humour on the part of the nurses. Two of the patients used black humour in referring to their own serious and incurable condition. I can only speculate about this. Maybe the patients introduced black humour as a way of approaching or deflecting a difficult topic.

\subsection{Small talk}

Sociolinguists point out that small talk has variously been described as formulaic, peripheral, minor, unimportant, but note that it might be better described as off-topic chat not concerned with the explicit purpose for which the speakers are together (Coupland, 2000). In fact small talk serves many important functions and can be crucial to the nurse achieving her work (Holmes, 2000). Small talk helps accomplish social goals such as "putting people at ease, building connection, winning approval and predisposing a listener to one’s perspective” (Tracy \& Naughton, 2000 p.63).

In the example which follows several of these goals are being fulfilled.

Example 6.5 Context: Nurse and patient are well into their conversation when the patient's husband appears. This fragment of conversation happens as an aside.

[DN02-01 Transcription p.11]

$\begin{array}{lll}1 & \text { Nurse } & \text { hello Jack } \\ 2 & \text { Jack } & \text { hello how are you } \\ 3 & \text { Nurse } & \text { what are you doing up there on the roof } \\ 4 & \text { Jack } & \text { oh cleaning the spouting out } \\ 5 & \text { Nurse } & \text { oh [laughs] + } \\ 6 & \text { Jack } & \text { yes }\end{array}$


7 Nurse what a household I come here one's on her hands and knees washing the kitchen

floor and the other one's scrubbing the roof

8 Jack [laughs]

9 Nurse do you think you're only twenty one or something [laughs]

To the onlooker this is a casual inconsequential aside to the main conversation. In line 3 the nurse deflects attention away from herself and asks him what he is doing. By asking the question, the nurse is showing an interest in his activity and making sure he knows he is included in the conversation. A holistic approach to health, which underlies nursing practice, naturally includes family members as part of the patient's world.

As discussed earlier in the section on commentary, small talk can 'normalise' unpleasant procedures. On the other hand small talk can be a used as a strategy by which unpleasant topics can be avoided. So there are times when small talk is used to avoid 'big talk'.

In the next example it is the absence of small talk where it would normally be expected which adds immediacy and concern to this exchange.

Example 6.6 Context: The nurse is approaching the open front door [DN01-01 Transcription p.4]

\begin{tabular}{lll} 
& Nurse & good morning \\
2 & Patient & good morning \\
3 & Nurse & is it a smile? \\
4 & Patient & yes \\
5 & Nurse & wonderful \\
6 & Patient & it's working like a dream \\
7 & Nurse & how fantastic Louise. Can I remind you I've got the thingy on \\
8 & Patient & yeah, yeah sure \\
9 & Nurse & that's great, okay, hullo cat, okey doke \\
\hline 0 & Patient & you haven't got time for a cuppa or \\
& Nurse & no I'm fine for fluids this morning, how about you
\end{tabular}

With virtually no preliminaries the nurse asks, "Is it a smile?” This extremely economical opening remark serves many functions. It is a variant of "How are you?" but more than a greeting. Here the nurse is eliciting information from the patient, determining whether things are going well or otherwise and in doing this she is also gauging the effectiveness of her advice given on the previous visit.

By convention conversations have openings and closings often categorised as small talk. The minimal small talk here gives the impression that the nurse is resuming a conversation 
after a brief break although it was in fact two days earlier. It suggests that what we are hearing is a fragment of a continuing conversation. A continuing conversation in turn implies that the nurse has remained with the patient and there has been no break in the continuity of care. This is an interesting use of a linguistic convention as a tool and the nurse uses the convention to create the illusion of continuity of care. It is particularly apt at this point in the patient's recovery. The transition from hospital to home, which the patient has just made, is a stressful time. It involves adjusting from an environment where there was constant help at hand to an acceptance of personal responsibility. The notion of constant care is highly desirable at this point.

\subsection{Strategic use of multifunctional questions}

On the surface, a significant part of the conversations appear to consist of inconsequential small talk. They are in fact scattered with multifunctional or ambiguous questions which fulfil an important purpose. These questions occur throughout the conversations and seem to be used most often for eliciting information while simultaneously furthering the relational work so crucial to district nursing.

Example 6.7 Context: Domiciliary visit to a patient with chronic respiratory disease. Checking the oxygen equipment.

[DN02-03 Transcription p.29]

$\begin{array}{lll}1 & \text { Nurse } & \text { how does your little dog like this tubing } \\ 2 & \text { Patient } & \text { oh he hates that } \\ 3 & \text { Nurse } & \text { does he yeah } \\ 4 & \text { Patient } & \text { yeah }\end{array}$

Line 1 may have been intended and heard as a piece of small talk. It may have been acknowledging that pets are part of the family but the nurse may also have been commenting on how the tubing has been chewed up or she may have been fishing for an explanation for the oxygen being used far less than the prescribed time.

Example 6.8 Context: The nurse is still getting to know this patient and wants to find out how she is coping with convalescence. She uses a general question to open up discussion [DN01-01 Transcription p.8]

1 Nurse good so what have you got organised for today 
While this is a question intended and heard as a casual friendly inquiry, for the nurse it is also loaded with potential for harvesting information. It functions as a means of eliciting information but also fulfils a relational function. The patient replies that her friend has a day off work so they will probably do some errands and see a movie. From this reply the nurse gets a sense of the patient's energy levels, mood, social network and confidence to go out. These are all significant markers of her convalescence and recovery.

In the next example the patient is discussing use of morphine to relieve troublesome ongoing symptoms. The patient speaks with a tone of sadness and resignation and the nurse is gently exploring this.

Example 6.9 Context: Discussing difficulties of a chronic illness [DN02-01 Transcription p.6]

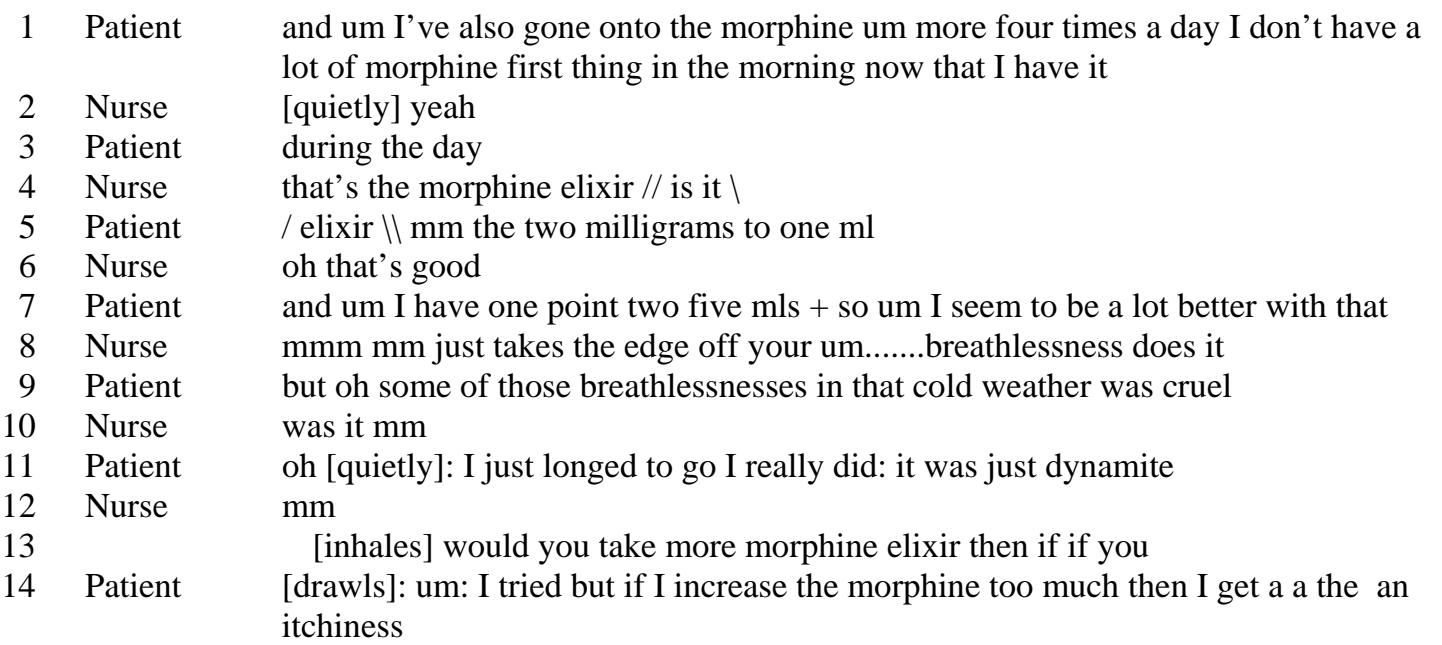

At line 13 the nurse leaves her question open to be interpreted in whatever way the patient decides. The nurse wants to help find a solution for the symptoms and needs to know how effective the morphine has been so far.

\subsection{Teachable Moments}

Expert nurses recognise and use the moment when a patient is ready to learn a new skill or absorb new information. This is what Johnson (1993) calls the 'teachable moment'. As she 
says, "taking advantage of the teachable moment was concomitant with trying to help patients gain a sense of control over a situation that seemed overwhelming to them”.

Nurses identify such opportunities when patients state a misconception or raise a question.

Example 6.10 Context: discussing the use of portable oxygen (oxylite) for outings [DN02-01 Transcription p.29]

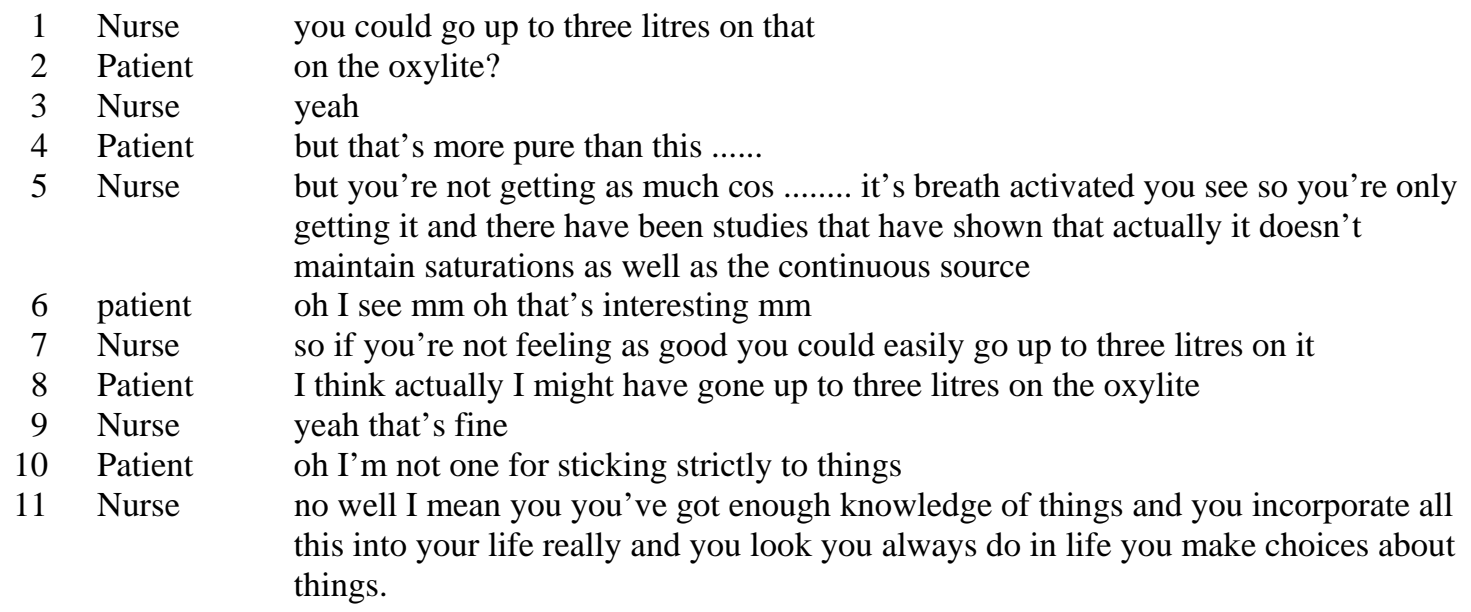

The teachable moment happens at Line 5 where the nurse shares some technical information with the patient. The nurse corrects a misconception (that oxylite is more 'pure' than the oxygen from the concentrator) without condescending and while taking care to avoid damaging the patient's sense of control or self-esteem.

As the nurse concludes this excerpt in Line 11 she acknowledges that the patient has “enough knowledge of things" and will "make choices about things”. In saying this the nurse is acknowledging the patient's right to have control over their own care and she is indicating her acceptance that the choice lies within the bounds that are acceptable to her.

I expected to find more teachable moments in the data than I did. I can only speculate that teaching happens more obviously in the initial few visits rather than when nurses and patients know each other fairly well. Possibly it is a measure of expertise that the teachable moments are so few, and patients are guided by experts toward their own solutions rather than having solutions imposed. 


\subsection{Discussion}

The examples from the transcripts show that in order to achieve the purpose of their conversations, nurses used various strategies. These were:

- matching voice tone and rate

- commentary

- humour

- $\quad$ small talk

- strategic use of multifunctional questions

- teachable moments

Every conversation included examples of these strategies. The strategies served a variety of purposes and often had multiple effects.

On listening to the recorded conversations it is clear that the nurses matched their voice tone and rate with that of the patients. In linguistic terms, this signifies accommodation between speakers and points to a cooperative, collaborative, interaction.

Commentary was employed either in association with a physical task or as a means of representing information to the patient to provide fresh insight on their situation. The way these nurses used commentary demonstrated their commitment to working in partnership with their patients.

The nurses used humour sparingly. This is in keeping with the findings of Hinckley, Craig and Anderson (1990), who state that patients prefer friendliness, seriousness and concern (p 520).

Analysis of the data revealed how small talk in particular fulfilled many functions: it helps to accomplish social goals by putting people at ease and building connection, it functions as a means of both approaching and avoiding more serious or challenging topics.

Relational practice, which has not previously been given a lot of attention as a component of nursing conversations, is also shown to be used as a linguistic strategy, to build and maintain relationships. This kind of work was evident, although not immediately obvious, throughout the data. 


\section{Chapter 7}

\section{Discussion,}

\section{Recommendations}

\section{and Summary}

\subsection{Discussion}

The study has shown that in their interactions with patients, expert nurses follow a pattern in terms of the structure and content of the conversations and it is possible to identify specific features of effective nurse-patient communication within these conversations. These are findings which can be incorporated into education programmes for nurses.

I started this research as an appreciative enquiry, identifying and building on the positive aspects of what I was observing and hearing. Appreciative enquiry naturally imposes some reticence in naming or drawing attention to poor communication. 
Yet even where there is excellent practice there can be lapses or areas for development. For instance, the nurse may say things, which might be perceived as unhelpful.

There were times in the study where the communication may have been perceived as counterproductive. For example the use of 'Good Girl' by the nurse might signify a change in power, diminishing the confidence and esteem in the patient, and could be perceived as patronising. Or there could be lack of focus and clarity through unfinished sentences, which might mean that the patient is left feeling unsure of the message.

The instances were few yet one of the questions I have is how might practitioners become aware of what they are saying and whether these instances have detrimental effects on the patient? How do nurses in general reflect on their communication and its effect when no one is there to give feedback? The methodology used in this study offers a solution to this question.

There is a need for nurses to develop self- awareness in the area of verbal skill and in the potential for different interpretations of what you understand as a perfectly commonplace word such as ....( medical terms) chronic / acute....(colloquial language ) my dear / good girl. There could be growth and development even in the most experienced practitioners and where practice is excellent.

Because language is living and constantly changing and because the data in this study was analysed and interpreted in relation to a specific time and context, readers must be mindful of the possible limits this imposes on future applications of the findings.

A potential weakness in the study is the assumption that expert nurses will be expert communicators. As discussed in chapter 3 the nurse participants were selected from a group of nurses with a track record of good clinical outcomes. I have confidence in their ability as expert communicators due to their known success in terms of clinical outcomes in a field of nursing which is heavily dependent on communication skill.

Effective communication is highly valued by patients and families and is frequently noticed and commented upon over and above physical and technical procedures. 


\subsection{Recommendations}

There are lessons here for nurse practitioners (both novice and expert), nurse educators, nurse managers and researchers.

\subsubsection{Practitioners.}

The data in this study shows that expert nurses, despite enormous variation in the nature of their verbal interactions, nevertheless follow a pattern in their talk with patients. The pattern takes the form of: negotiating the agenda, eliciting information, doing a physical examination and planning care. Identifying this pattern is useful as a guide for novice nurses who are learning how to approach a domiciliary visit. For expert nurses the pattern acts as a standard against which practice can be measured. And the process of reviewing and reflecting on a recorded interaction is a valuable means of affirming effective practice and identifying areas to be improved.

These features of effective nurse-patient communication can be identified and learned. The use of effective language is not only a skill which nurses can add to their repertoire but it can also be used as a measure of nursing expertise. In their professional development nurses benefit from opportunities to review and reflect on their practice. This work suggests that hearing a recorded interaction could be incorporated as part of the process of achieving this.

\subsubsection{Nurse Educators}

As well as the pattern to the conversations already mentioned above, there are specific communicative strategies which can be taught for example the use of open questions and the use of commentary, multifunctional questions and the technique of matching voice pitch and rate. Recognising and naming these features of nurse-patient interaction in itself raises awareness of how verbal communication can have an impact on the whole episode of care. 
This thesis exposes the potential therapeutic effect of the 'everyday' conversations between nurses and patients. In particular it draws attention to the way in which small talk and commentary can enhance the purpose of nursing.

\subsubsection{Nurse managers}

Even the best nurse communicators need support in order to be effective. Practical measures are necessary such as having sufficient time and psychological support. This is especially so in the obvious cases of breaking bad news or dealing with an angry patient. Parle, Maguire \& Heaven (1997) explain that lack of support in the workplace is more likely to lead to distancing tactics being used by the nurse and this diminishes her ability to be therapeutic.

Another finding of this research, which has implications for nurse managers, is the importance of having a clear professional philosophy or set of beliefs and attitudes that underpin nursing practice. These, along with practical support are the elements nurse managers can foster and maintain in order to promote effective nurse-patient communication.

\subsubsection{Researchers}

It was pleasing to discover how readily patients and nurses agreed to be recorded for this study. Any apprehension I had about their willingness to participate was quickly dissipated. Because of the methodology, which maximises the control participants have over data collection, I have no hesitation in recommending this as a research process.

There is potential for this study to contribute to a much more substantial work on nursepatient communication. It would be useful to repeat the study using a larger group of participants, including novice nurses, and a different setting for example a hospital ward. A priority would be to seek the patients' viewpoint when analysing the data.

The study provides a starting point, a contribution to much more which could be done on the same subject. 


\subsection{Summary}

This study was born of a belief that the communication skills of nurses affect the clinical outcomes for their patients. As a first approach to this hypothesis, I have examined the literature on the characteristics of effective communication, have devised a field investigation of actual nurse-patient communication and have analysed the data for significant features.

A review of the literature indicated that effective communication is important for patients, nurses and the positive outcomes of health care. In some circumstances, communication actually constitutes nursing care.

However much of that literature about nurse-patient and doctor-patient communication focuses on the failures or shortcomings of this activity and what might or should be done to remedy the situation. The literature is sporadic with little evidence of dialogue, development or comparisons between studies. There is a gap in our knowledge of the actual features of expert nurse-patient communication.

In this thesis I have attempted to determine and examine these features. I have recorded the interactions of expert nurses with patients as they occurred in everyday practice. Six conversations involving two nurses and four patients were transcribed and analysed using a combination of ethnographic and discourse analysis.

The analysis showed that all conversations had a number of common features. Interesting and unexpected findings were the relatively small use of humour and, more importantly, the distribution of talk between the participants as discussed in the analysis chapters. Communicative strategies were identified and found to be common to all conversations. These were: the use of humour, small talk, commentary, accommodation and multifunctional questions. The nurses also recognised and used 'teachable moments' in the conversations.

As described by Johnson (1993) every conversation followed a pattern in terms of its structure and content. This included: negotiating the agenda, eliciting information, doing a physical examination and planning future care. 
In addition, I found another feature which seemed to be an essential ingredient in the accomplishment of nursing goals: relational practice. Relational practice is the communication work that goes in to build the relationship between carers and patients, that supports their mutual activities and endeavours and goes largely unnoticed. Relational practice encompassed both the transactional and social elements of the conversations. Nurses used relational skills to build rapport, avoid or repair misunderstandings and enhance the patient's own ability to manage their health.

The findings indicate that while the conversations may appear to be predominantly light, superficial and inconsequential, the nurse is working in a complex and effective way to achieve a therapeutic outcome. 


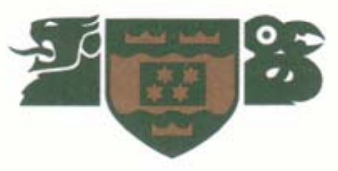

January 2001

\section{Information Sheet}

\section{Language in the Workplace: Research study into features of effective nurse-patient communication}

I am inviting you to take part in a study of nurse/patient communication.

I am a registered nurse and have been working as a district nurse for the last 10 years. As part of a Masters degree in nursing I would like to study how nurses communicate with patients. This is a small study, undertaken in the Wellington area and focussing on the ways nurses communicate. The material gathered in this study will also contribute to a larger one on communication in healthcare being undertaken by Victoria University's Language in the Workplace Project.

\section{How is the study carried out?}

If you agree to participate, your conversation will be tape recorded using a little lapel microphone and walkman.

You are free to delete material at any stage during taping or before you pass the tape to me or before the analysis.

The tape-recording will be transcribed so that it can be analysed for linguistic features.

When it is transcribed, pseudonyms will be used and all identifying features of the conversation will be removed to preserve your anonymity and our guarantee of confidentiality. No material which could personally identify you will be used in any reports on this study.

What happens to the tape? The tape recording is kept securely in a locked cabinet. It will be destroyed within 5 years.

Your participation is entirely voluntary. You do not have to take part in this study and if you choose not to take part this will not affect your care/employment in any way.

You are free to withdraw from the study at any time without having to give a reason.

\section{What happens to the results?}

The results of the study will be reported in a university dissertation and I will also write a brief readable report which will be sent to those participants who want it.

\section{Where can I get more information about the study?}

Lindsay Macdonald RGON BN

ph 3855821 (work)

Lindsay.Macdonald@wnhealth.co.nz

Or Wellington Ethics Committee, Wgtn Hospital, ph 3855999 ext. 5185. ph 4635614 (work)

Janet.Holmes@vuw.ac.nz
Professor Janet Holmes

GRADUATE SCHOOL OF NURSING AND MIDWIFERY

P.O. Box 600, Wellington, New Zealand, Telephone +64-4-4635363 Or Freephone 0800108005

Facsimile+64-4-463 5442, E-mail Nursing-Midwifery@vuw.ac.nz 


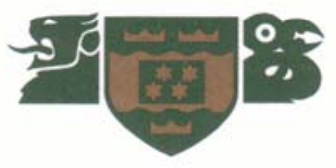

\section{Consent Form}

\section{Language in the Workplace: Research study into features of effective nurse-patient communication}

I have read and I understand the information sheet dated January 2001 for volunteers to take part in this communication study.

I have had an opportunity to discuss the study and I am satisfied with the answers I have been given.

I am aware that material collected for this study will contribute to the Language in the Workplace Study being done by Victoria University.

I understand that taking part in the study is voluntary (my choice) and that I may withdraw at any time without having to give a reason. If I withdraw it will not affect my care or employment in any way now or in the future.

I understand that my participation in this study is confidential and that no material which could identify me will be used in any reports on the study.

I have had time to consider whether to take part.

I know who to contact if I have any questions about the study.

I consent to having my conversation tape recorded.

I understand that the recording will be destroyed within 5 years.

I wish to receive a short report on the study. Yes/ No (please circle)

[Please provide a postal or email address if you circle "yes"]

Address:

I (full name)

take part in this study.

hereby consent to

\section{Signature}

Name of witness

Project explained by

Signature
Date

Signature

Project role 


\title{
Transcription Conventions
}

The conversation excerpts given in this thesis are set out using the following convention.

\author{
All names are pseudonyms \\ YES Capitals indicate emphatic stress \\ [laughs]:: Paralinguistic features/glosses in square brackets, colons indicate start and \\ finish \\ $+\quad$ Pause of up to one second \\ (3) Pause of specified number of seconds \\ ....//......... Simultaneous speech \\ .../............ \\ (hello) Transcriber's best guess at an unclear utterance \\ ? $\quad$ Rising or question intonation \\ - $\quad$ Incomplete or cut-off utterance \\ ........... Some slight editing has been undertaken for ease of reading e.g. reduction \\ of hesitation
}




\section{References}

Ainsworth-Vaughn, N. (1998). Claiming power in doctor: Patient talk. Oxford: OUP.

Alexander, I. M. (2001). Hearing womens' voices: Primary care interactions. Unpublished Ph.D., The University of Connecticut.

Andrews, C., Macdonald, L., \& Connor, M. (1998). Community health model of nursing practice. Wellington: Community Health Service, Capital Coast Health Ltd.

Barton, J A. Smith, M C Brown, N J, Supples, J M. (1993). Methodological issues in a team approach to community health needs assessment. Nursing Outlook. 41(6), 253261.

Benner, Patricia E. (1984). From novice to expert: excellence and power in clinical nursing practice. Meulo Park, California: Addison-Wesley Publishing Company.

Bjornsdottir, K. (1998). Language, ideology, and nursing practice...including commentary by Liaschenko J. Scholarly Inquiry for Nursing Practice, 12(4), 347-366.

Bjornsdottir, K. (2001). Language, research and nursing practice. Journal of Advanced Nursing, 32(2), 159-166.

Booth, K., Maguire, P., \& Hillier, V. F. (1999). Measurement of communication skills in cancer care: Myth or reality? Journal of Advanced Nursing, 30(5), 1073-1079.

Bottorf, J., Steele, R., Davies, B., Porterfield, P., Garossino, C., \& Shaw, M. (2000). Facilitating day-to-day decision making in palliative care. Cancer Nursing, 23(2), 141-150.

Bourhis, R., Roth, S., \& MacQueen, G. (1989). Communication in the hospital setting: A survey of everyday language use amongst patients, nurses and doctors. Social Science and Medicine, 28(4), 339-346.

Brown, S. J. (1995). An interviewing style for nursing assessment. Journal of Advanced Nursing, 21, 340-343.

Bruni, N. (1988). A critical analysis of transcultural theory. The Australian Journal of Advanced Nursing, 5 (3), 26-32.

Candlin, S. (2000). New dynamics in the nurse-patient relationship. In S. Sarangi, \& M. Coulthard, (Eds.), Discourse and social life (pp. 230-245). Harlow, UK: Pearson Education Limited.

Cartwright, S. (1988). The Report of the Cervical Cancer Inquiry. Auckland: Government Print. 
Castledine, G. (2002). Medical language must be clarified for patients. British Journal of Nursing, 11(16), 1106.

Central Regional Health Authority Wellington Ethics Committee. (1997). Guidelines for research applicants. Wellington: Author.

Channell, J. (1994). Vague language. Oxford: Oxford University Press.

Christensen, J. (1990). Nursing partnership: A model for nursing practice. Wellington: Daphne Brasell Associated Press.

Coupland, J. (2000). Small talk. Harlow, UK: Pearson Education Limited.

Coupland, J., Coupland, N., \& Robinson, J. (1992). "How Are You?": Negotiating phatic communion. Language in Society, 21, 207-230.

Coupland, J., Robinson, J., \& Coupland, N. (1994). Frame negotiation in doctor-elderly patient consultations. Discourse and Society, 5(1), 89-124.

Coupland, N., Wiemann, J.M. \& Giles, H. (1991). Talk as a "problem" and communication as "miscommunication": An integrative analysis. In N. Coupland, H. Giles, \& J.M. Wiemann (Eds.), "Miscommunication" and problematic talk (pp.1-17). London: Sage.

Dickson, D. (1995). Communication and interpersonal skills. In D. Sines (Ed.), Community health care nursing. Oxford: Blackwell Science.

Dill, A E P. (1995) The ethics of discharge planning for older adults: An ethnographic analysis. Social Science \& Medicine, 41(9),1289-1299.

Dobbin, J. (1990). First-name terms? Nursing Times, 86(22), 34.

Edwards, B., \& Brilhart, J. (1981). Communication in nursing practice. St Louis: The CV Mosby Company.

Fenwick, J., Barclay, L., \& Schmied, V. (2001). "Chatting": An important clinical tool in facilitating mothering in neonatal nurseries. Journal of Advanced Nursing, 33(5), 583-593.

Fletcher, J. (1999). Disappearing acts: Gender, power and relational practice at work. Cambridge, MA: MIT Press.

Fosbinder, D. (1994). Patient perceptions of nursing care: An emerging theory of interpersonal competence. Journal of Advanced Nursing, 20, 1085-1093.

Gibb, H. \& O'Brien, B. (1990). Jokes and reassurance are not enough: Ways in which nurses relate through conversation with elderly clients. Journal of Advanced Nursing, 15, 1389-1401. 
Gunther, M. \& Alligood, M. R. (2002). A discipline-specific determination of high quality nursing care. journal of Advanced Nursing, 38(4), 353-359.

Hammond, S. (1996). The thin book of appreciative inquiry. Plano, TX: ThinBook Publishing.

Haselfeld, D. (1990). Patient assessment. AORN, 52(3), 551-557.

Heaven, C.M. \& Maguire, P. (1996). Training hospice nurses to elicit patient concerns. Journal of Advanced Nursing, 23, 280-286.

Hinckley, J., Craig, H., \& Anderson, L. (1990). Communication characteristics of provider-patient information exchanges. In H. Giles \& W. P. Robinson (Eds.), Handbook of language and social psychology. Chichester: John Wiley and Sons.

Holland, C. (1993). An ethnographic study of nursing culture as an exploration for determining the existence of a system of ritual. Journal of Advanced Nursing. 18, 1461-1470.

Holmes, J. (1992). An introduction to sociolinguistics. Harlow: Longman Group UK Limited.

Holmes, J. (2000). Doing collegiality and keeping control at work: Small talk in government departments. In J.Coupland (Ed.), Small talk. Harlow,UK: Pearson Education Limited.

Holmes, J. (2001). Introduction to sociolinguistics. 2nd Edition London: Longman.

Hunt, M. (1991). Being friendly and informal: Reflected in nurses', terminally ill patients' and relatives' conversations at home. Journal of Advanced Nursing, 16, 929-938.

James, D., \& Clarke, S. (1992). Interruptions, gender, and power: A critical review of the literature. In K. Hall, M. Bucholtz, \& B. Moonwomon (Eds.), Locating power. Proceedings of the Second Berkley Women and Language Conference. April 4 and 5 1992. Vol 1 (pp. 286-299). Berkley: Berkley Women and Language Group.

James, D., \& Drakich, J. (1993). Understanding gender differences in amount of talk. In D. Tannen (Ed.), Gender and conversational interaction (pp. 281-312). Oxford: Oxford University Press.

Jarrett, N., \& Payne, S. (1995). A selective review of the literature on nurse-patient communication: Has the patient's contribution been neglected? Journal of Advanced Nursing, 22, 72-78.

Johnson, R. (1993). Nurse practitioner-patient discourse: Uncovering the voice of nursing in primary care practice. Scholarly Inquiry for Nursing Practice: An International Journal, 7(3), 143-163. 
Kasch, C. R. (1986). Toward a theory of nursing action: Skills and competency in nursepatient interaction. Nursing Research, 35(4), 226-230.

Leininger, M. (1970) Nursing and anthropology: Two worlds to blend. New York: John Wiley and Sons.

Leininger, M. (1978) Transcultural nursing. New York: Wiley

Leininger, M. (1991) Culture care diversity and universality: A theory of nursing. New York: NLN Press.

Leininger, M. (1996) Response to Swendson and Windsor: Rethinking cultural sensitivity. Nursing Inquiry, Vol 3 p 238-241.

Leininger, M. (2001) Response and reflection on Bruni's 1988 critique of Leininger's theory. Collegian, Vol 8 Issue 1 p37-38.

Lore, A. (1981). Effective therapeutic communications. Unpublished manuscript, Maryland.

Luker, K. A. \& Chalmers, K. (1990). Gaining access to clients: The case of health visiting. Journal of Advanced Nursing, 15, 74-82.

Luker, K.A., Austin, L., Caress, A., \& Hallett, C.E. (2000). The importance of 'knowing the patient': community nurses' construction of quality in providing palliative care. Journal of Advanced Nursing, 31, 775-782.

Mackenzie, A. E. (1994). Evaluating ethnography: Considerations for analysis. Journal of Advanced Nursing, 19, 774-781.

Macleod Clark, J. (1984). Verbal communication in nursing. In A. Faulkner (Ed.), Recent advances in nursing Communication (Vol. 7). Edinburgh: Churchill Livingstone.

Maguire, P., Faulkner, A., Booth, K., Elliot, C., \& Hillier, V. (1996). Helping cancer patients disclose their concerns. European Journal of Cancer, 32A(1), 78-81.

May, C. (1992). Nursing work, nurses' knowledge, and the subjectification of the patient. Sociology of Health and Illness, 14(4), 472-487.

Mishler, E. G. (1984). The discourse of medicine dialectics of medical interviews. Norwood, NJ: Ablex Publishing Corporation.

Morton, A., \& Mackenzie, A. (1994). An exploratory study of the consumers' views of carer support groups. Journal of Clinical Nursing, 3(1), 63-64.

Nightingale, F. (1860). Notes on nursing (Dover ed., 1969). New York: Dover Publications.

Norton, S., \& Talerico, K. (2000, September). Facilitating end-of-life decision-making. Journal of Gerontological Nursing, 6-13. 
Paltridge, B. (2000). Making sense of discourse analysis (Book 3 of Making Sense of Language Series). Brisbane: Antipodean Educational Enterprises.

Parker, J., \& Gardner, G. (1991-1992). The silence and the silencing of the nurse's voice: A reading of patient progress notes. The Australian Journal of Advanced Nursing, 9(2), 3-9.

Parle, M., Maguire, P., \& Heaven, C. (1997). The development of a training model to improve health professionals' skills, self-efficacy and outcome expectancies when communicating with cancer patients. Social Science and Medicine, 44(2), 231-240.

Saville-Troike, M. (1982). The ethnography of communication (Vol. 2). Oxford: Blackwell.

Simpson, M., Buckman, R., Stewart, M., Maguire, P., Lipkin, M., Novack, D., \& Till, J. (1991). Doctor-patient communication: The Toronto consensus statement. British Medical Journal, 303, 1385-1387.

Spender, D. (1980). Man made language. London: Routledge \& Kegan Paul Ltd.

Srivastva, S., Cooperrider, D. L., \& Associates (Eds.). (1990). Appreciative management and leadership: The power of positive thought and action in organizations (1st ed.). San Francisco, CA: Jossey-Bass Inc.

Street, R. L. Jr. (1991). Accommodation in medical consultations. In H.Giles, J. Coupland, \& N. Coupland (Eds.), Contexts of accommodation developments in applied sociolinguistics (pp.131-156). Cambridge: Cambridge University Press.

Strong, F. (1985). Mind your language. AID Magazine: Advancing the Interests of Disabled, 25 , 41.

Stubbe , M. (1998, July). Researching language in the workplace: A participatory model. In Proceedings of the Australian Linguistics Society Conference, Brisbane: University of Queensland. [Accessed from http://www.cltr.uq.au/als98/]

Swendson, C., \& WIndsor, C. (1996). Rethinking cultural sensitivity. Nursing Enquiry, 3, 3-10.

Tannen, D. (1990). You just don't understand: Women and men in conversation. New York, William Morrow.

Tracy, K. \& Naughton, J. (2000). Institutional identity-work: A better lens. In J.Coupland (Ed.), Small talk. Harlow, UK: Pearson Education Ltd.

Tulin, M. F. (1997). Talking organisation. Possibilities for conversation analysis in organisational behaviour research. Journal of Management Inquiry, 6, 101-119. 
van Dijk, T. (1998). Principles of critical discourse analysis. In J. Cheshire \& P. Trudgill (Eds.), The sociolinguistics reader, Vol. 2. Gender and discourse (367-393). London: Arnold.

Vancott, M. L. (1989). Analyzing nursing communicative competence with the hospitalised elderly. Unpublished PhD, University of Florida.

Waterworth, S. \& Luker, K. (1990). Reluctant collaborators: Do patients want to be involved in decisions concerning their care? Journal of Advanced Nursing, 15, 971976.

West, C. (1984). When the doctor is a "lady": Power, status and gender in physicianpatient encounters. Symbolic Interaction, 7(1), 87-106.

West, C. (1995). Women's Competence in conversation. Discourse and Society, 6(1), 107131.

Wodak, R. (1996). Disorders of discourse. New York: Addison Wesley Longman Limited. 


\section{Bibliography}

The following papers and books are not referred to directly in the text. They have been useful sources of additional information on related topics and may be of interest to other investigators:

Ainsworth-Vaughn, N. (1992). Topic transitions in physician-patient interviews: Power, gender, and discourse change. Language in Society, 21, 409-426.

Allen, M. J. (1993). Sociolinguistic dimensions of nurse practitioner practice: A question of power. D. N. Sc. Thesis, University of San Diego, San Diego, CA.

Bailey, P. H. (1997). Finding your way around qualitative methods in nursing research. Journal of Advanced Nursing ,25(1),18-22.

Bottorf, J., \& Morse, J. (1994). Identifying types of attending: Patterns of nurses' work. Image Journal of Nursing Scholarship, 26(1), 53-60.

Buresh, B., \& Gordon, S. (1995, March). Nursing in the right Words. American Journal of Nursing, 20-22.

Buresh, B., \& Gordon, S. (1996). Subtle self-sabotage. American Journal of Nursing, 96(4), 22-24.

Caris-Verhallen, W., de Gruiter, I., Kerkstra, A., \& Bensing, J. (1999). Factors related to nurse communication with elderly people. Journal of Advanced Nursing, 30(5), 1106-1117.

Caris-Verhallen, W., Kerkstra, A., \& Bensing, J. (1997). The role of communication in nursing care for elderly people: a review of the literature. Journal of Advanced Nursing, 25(5), 915-933.

Cowley, S., \& Casey, A. (1995). The language of community nursing. In J. Littlewood (Ed.), Current issues in community nursing (pp. 23-51). Edinburgh: Churchill Livingstone.

Davis, K. (1988). Paternalism under the microscope. In A. Todd \& S. Fisher (Eds.), Gender and discourse: The power of talk (Vol. XXX). Norwood, NJ: Ablex Publishing Corporation.

Ervin-Tripp, S. (1976). Is Sybil there? The structure of some American English directives. Language in Society, 5, 25-66.

Fine, J. (Ed.). (1988). Second language discourse: A textbook of current research (Vol. $X X V)$. Norwood, NJ: Alex Publishing Corporation. 
Fisher, S. (1991). A discourse of the social: Medical talk/power talk/oppositional talk? Discourse and Society, 2(2), 157-182.

Fisher, S. (1995). Nursing wounds nurse practitioners, doctors, women patients and the negotiation of meaning. New Brunswick: Rutgers University Press.

Froggatt, K. (1998). The place of metaphor and language in exploring nurses' emotional work. Journal of Advanced Nursing, 28(2), 332-338.

Gelling, L. (1999). Ethical principles in healthcare research. Nursing Standard, 13(36), 3942.

Gerrish, K. (2001). The nature and effect of communication difficulties arising from interactions between district nurses and South Asian patients and their carers. Journal of Advanced Nursing, 33(5), 566-574.

Jaworski, A. (1993). The power of silence (Vol. 1). Newbury Park, CA: Sage Publications.

Kauffman, K. (1994). The insider/outsider dilemma: Field experience of a white researcher "getting in" in a poor black community. Nursing Research, 43(3), 179183.

Kilkelly, K. M. (1992). Patterns of self-disclosure: An ethnographic account of conversation about health among Irish women. Ed.D Thesis, Columbia University Teachers College, New York.

Labov, W. (1972). Some principles of linguistic methodology. Journal of Language and Social Psychology, 1, 97-120.

Milroy, L. (1987). Observing and analysing natural language. Oxford: Basil Blackwell Ltd.

Mooney, M. (1980). Directives as a speech function: an examination of the structure of directives in a New Zealand psychiatric clinic. Unpublished paper, available from the Linguists Department, Victoria University of Wellington, Wellington, NZ.

Morrison, P., \& Burnard, P. (1989). Students' and trained nurses' perceptions of their own interpersonal skills: A report and comparison. Journal of Advanced Nursing, 14, 321-329.

Porritt, L. (1984). Communication choices for nurses. Melbourne: Churchill Livingstone.

Ragan, S. (2000).Sociable talk in women's health care contexts: Two forms of nonmedical talk. In J.Coupland (Ed.), Small talk. Harlow,UK: Pearson Education Limited.

Thomas, J. (1995). Meaning in interaction: An introduction to pragmatics. London: Longman. 
West, C., \& Garcia, A. (1988). Conversational shift work: A study of topical transitions between women and men. Social Problems, 35(5), 551-575.

Wilkinson, S. (1991). Factors which influence how nurses communicate with cancer patients. Journal of Advanced Nursing, 16, 677-688.

Wolfson, N. (1988). The bulge: A theory of speech behaviour and social distance. In J. Fine (Ed.), Second Language Discourse: A Textbook of Current Research (Vol. $X X V)$, (pp. 21-39). Norwood, NJ: Ablex Publishing Corporation. 